\title{
The digital terrain model in the computational modelling of the flow over the Perdigão site: the appropriate grid size
}

\author{
José M. L. M. Palma ${ }^{1}$, Carlos A. M. Silva ${ }^{1}$, Vítor C. Gomes ${ }^{1}$, Alexandre Silva Lopes ${ }^{1}$, Teresa Simões ${ }^{2}$, \\ Paula Costa ${ }^{2}$, and Vasco T. P. Batista ${ }^{1}$ \\ ${ }^{1}$ Faculty of Engineering of the University of Porto (FEUP), Mechanical Engineering Department, \\ Rua Dr. Roberto Frias, s/n, 4200-465 Porto, Portugal \\ ${ }^{2}$ National Laboratory of Energy and Geology (LNEG), \\ Estrada da Portela, Bairro do Zambujal, Apartado 7586, Alfragide, 2610-999 Amadora, Portugal
}

Correspondence: José Manuel Laginha Mestre da Palma (jpalma@ fe.up.pt)

Received: 30 November 2019 - Discussion started: 3 March 2020

Revised: 30 June 2020 - Accepted: 8 September 2020 - Published: 5 November 2020

\begin{abstract}
The digital terrain model (DTM), the representation of earth's surface at regularly spaced intervals, is the first input in the computational modelling of atmospheric flows. The ability of computational meshes based on high- ( $2 \mathrm{~m}$; airborne laser scanning, ASL), medium- (10 m; military maps, Mil) and low-resolution (30 m; Shuttle Radar Topography Mission, SRTM) DTMs to replicate the Perdigão experiment site was appraised in two ways: by their ability to replicate the two main terrain attributes, elevation and slope, and by their effect on the wind flow computational results. The effect on the flow modelling was evaluated by comparing the wind speed, wind direction and turbulent kinetic energy using $\operatorname{VENTOS}^{\circledR} / 2$ at three locations, representative of the wind flow in the region. It was found that the SRTM was not an accurate representation of the Perdigão site. A $40 \mathrm{~m}$ mesh based on the highest-resolution data yielded an elevation error of less than $1.4 \mathrm{~m}$ and an RMSE of less than $2.5 \mathrm{~m}$ at five reference points compared to $5.0 \mathrm{~m}$ in the case of military maps and $7.6 \mathrm{~m}$ in the case of the SRTM. Mesh refinement beyond $40 \mathrm{~m}$ yielded no or insignificant changes on the flow field variables, wind speed, wind direction and turbulent kinetic energy. At least $40 \mathrm{~m}$ horizontal resolution - threshold resolution based on topography available from aerial surveys is recommended in computational modelling of the flow over Perdigão.
\end{abstract}

\section{Introduction}

A digital terrain or digital elevation model (DTM or DEM) is a representation of the earth's surface elevation at regularly spaced horizontal intervals. Although the terrain model is the first input in computational modelling of atmospheric flows, its impact on flow results has not been a matter of concern because the spatial resolution of publicly available DTMs is higher than the size of the computational grid often used to resolve the terrain. However, before a fluid flow database (Mann et al., 2017) can be used as a reference in flow model appraisal and development, the impact of the terrain modelling must be assessed. For studies of the atmospheric flow over Perdigão the publicly available DTMs were considered not accurate enough (Mukherjee et al., 2013; Simpson et al., 2015), and an airborne laser scanning (ASL) campaign of the region was carried out in 2015, first to assist the design of the Perdigão campaigns in 2015 and 2017 (cf., Vasiljević et al., 2017; Fernando et al., 2019) and second to provide the highresolution terrain data for computational flow modelling, on par with the resolution provided by the large amount of measuring equipment within a small region.

The Perdigão site is located in the municipality of Vila Velha de Ródão, in the centre of Portugal (4396621N, 608250E: ED50 UTM 29N or, in WGS84, $39^{\circ} 42^{\prime} 38.5^{\prime \prime} \mathrm{N}$ $\left.7^{\circ} 44^{\prime} 18.5^{\prime \prime} \mathrm{W}\right)$. It is comprised of two parallel ridges at about 
$500 \mathrm{~m}$ elevation, $4 \mathrm{~km}$ in length, with a SE-NW orientation and distanced around $1.4 \mathrm{~km}$ from each other. The land is covered by a mixture of farming areas and patches of eucalyptus (Eucalyptus globulus) and pine trees (Pinus pinaster). The dominant winds are perpendicular to the ridges, assuring a largely two-dimensional flow.

The accuracy of a DTM depends on the data collection techniques, data sampling density and data post-processing, such as grid resolution and interpolation algorithms. In computational modelling of atmospheric flows, DTMs are often used from photogrammetry or satellite interferometry, such as the SRTM (Shuttle Radar Topography Mission; Farr et al., 2007) or ASTER (Advanced Spaceborne Thermal Emission and Reflection Radiometer; Yamaguchi et al., 1998), freely available at https://earthexplorer.usgs.gov/ (last access: 16 October 2020). The SRTM has the widest cover and is the most commonly used terrain data set. Its latest version (V3.0 1", 2014) is 1 arcsecond on most of the planet's surface, i.e. about $27 \mathrm{~m} \times 31 \mathrm{~m}$ resolution and an absolute height error equal to $6.2 \mathrm{~m}$ at Perdigão's latitude (Farr et al., 2007). With the advent of high-resolution techniques such as lidar aerial survey, terrain data have become available with resolutions above $10 \mathrm{~m}$ and vertical accuracy typically below $0.2 \mathrm{~m}$ (Hawker et al., 2018), and the question is whether such high resolution is needed in the computational modelling of atmospheric flows over complex terrain.

\subsection{Literature review}

Grid-independent calculations are a concept very dear to computational fluid dynamics practitioners (e.g. Roache, 1998) as a means for reducing discretization errors. However, its application in the context of atmospheric flows is not that simple because every level of grid refinement brings another level of surface detail; see for instance the coastline paradox (Mandelbrot, 1967, 1982). In this case, because the flow is driven by topography, the flow model results are directly correlated to the terrain data, and our problem is common to what can be encountered in geomorphology, with applications in hydrology (e.g. Zhang and Montgomery, 1994; Wise, 2000; Deng et al., 2007; Savage et al., 2016), where the DTM grid size affects the drainage area. In spite of its importance, to our knowledge, there is no systematic study on the appropriate grid size for resolving the terrain in microscale modelling of atmospheric flow over complex terrain.

Work has been done on quantifying the impact of using different DTMs and resolution on terrain attributes, such as elevation, slope, plan and profile curvature, and topographic wetness index. For instance, Mahalingam and Olsen (2016) note that DEMs are often obtained and resampled without considering the influence of their source and data collection method. Finer meshes do not necessarily mean higher accuracy in prediction (with examples for landslide mapping where terrain slope has a great influence), with the DEM source being an important consideration.
DeWitt et al. (2015) compared several DEMs (USGS, SRTM, a statewide photogrammetric DEM and ASTER) to a high-accuracy lidar DEM to assess their differences in rugged topography through elevation, basic descriptive statistics and histograms. Root mean square error ranged from 3 (using a photogrammetric DEM) to approximately 15 (using the SRTM) or $17 \mathrm{~m}$ (using ASTER).

Deng et al. (2007) indicated that the mesh resolution can change not only terrain attributes in specific points but also the topographic meaning of attributes at each point. They concluded that variation in terrain attributes was consistent with resolution change and that the response patterns were dependent on the landform classes of the area. Deng et al. (2007) introduced the concept of threshold resolution, i.e. the resolution beyond which the model quality deteriorated quickly but below which no significant improvement in modelling results was observed.

Florinsky and Kuryakova (2000) developed an experimental three-step statistical method to determine an adequate DEM resolution to represent topographic variables and landscape properties at a microscale (exemplified by soil moisture) by performing a set of correlation analyses between resolutions.

Diebold et al. (2013) showed the effect of grid size in large-eddy simulation (LES) of flow over Bolund. Lange et al. (2017) addressed the question of how to represent the small topographic features of Bolund in wind tunnel modelling, comparing a round and a sharp edge of a cliff in a wind tunnel and concluding that the cliff with the sharp edge gives an annual energy production of a wind turbine near the escarpment that is $20 \%$ to $51 \%$ of the round-edge case.

\subsection{Objectives and outline}

The objective of the present study is to determine the terrain resolution required to accurately resolve the atmospheric flow over Perdigão and mountainous terrain in general. One needs to assess the terrain horizontal resolution before assessing the effect of other (also important) causes of differences between experimental and computational results. Many computational studies based on Perdigão data are expected, and it is important to assess the terrain resolution requirements first.

In what follows, we describe the techniques used for aerial and terrestrial surveying (Sect. 2) plus the post-processing of those data and the determination of the main geometrical parameters of the Perdigão site (Sect. 3). The results of terrain attributes and computational flow modelling are the subject of Sects. 4 and 5. The paper ends (Sect. 6) with conclusions and recommendations on the most appropriate DTM and grid size required in the computational modelling of the flow over Perdigão. 


\section{Topographical surveying: equipment and techniques}

\subsection{Airborne laser scanning (2015)}

The lidar aerial survey (Mallet and Bretar, 2009) was performed on 15 March 2015 by NIRAS (2015), with assistance from Blom TopEye. The survey covered an area equal to $22071075 \mathrm{~m}^{2}$ (Fig. 1) and was completed in one session at an altitude of $500 \mathrm{~m}$ with a TopEye system S/N 444 and a camera mounted on a helicopter. The number of points of the lidar point cloud was approximately 993198375 , an average point density inside the project area equal to 45 and 12.6 points $\mathrm{m}^{-2}$ if restricted to the groundclass points (Fig. 1a and Sect. 3.1). The photography (a total of 744 photos, stored as $300 \mathrm{~m} \times 300 \mathrm{~m}$ tiles) was performed with a Phase One iXA180 medium-format camera with 10328 pixel $\times 7760$ pixel sensor resolution, yielding a ground resolution equal to $4.7 \mathrm{~cm}$ (Fig. 1b).

Lidar data were checked for point density control by Blom's software TPDS (TopEye Point Density and Statistics), the area being fully covered by lidar data with exceptions for watersheds. GPS signal was processed using data from three Portuguese reference network stations (CBRA, MELR and PORT; cf. DGT, 2017) after assistance by the Portuguese National Mapping Agency (DireçãoGeral do Território, Divisão de Geodesia). Discrepancies between flight lines (based on Blom's software TASQ, TopEye Area Statistics and Qualities, calculated on sub-areas of $1 \mathrm{~m}$ and after matching of 204104275 observations) showed a maximum altitude deviation and RMSE equal to 0.490 and $0.061 \mathrm{~m}$. In $75 \%$ of the sub-areas, the RMSE was lower than $60 \mathrm{~mm}$.

The raw data of the NIRAS (2015) campaign comprised the lidar point cloud in LASer (LAS; version 1.2) format and the orthophotos in 20 and $5 \mathrm{~cm}$ resolution; for more information and availability on these data see Palma et al. (2020e). The production of the digital terrain model based on the lidar point cloud is the subject of Sect. 3.1.

\subsection{Terrestrial surveying (2017 and 2018)}

During the installation of scientific equipment (Nov 2016-May 2017), terrain elevation was measured in situ (Palma et al., 2018) for an accurate and final determination of the elevation data of part of the instrumentation. The measuring equipment was a Leica system comprised of the following units: (1) Leica Nova Multistation MS50 (http://w3.leica-geosystems.com/ downloads123/zz/tps/nova_ms50/white-tech-paper/Leica_

Nova_MS50_TPA_en.pdf, last access: 20 October 2020), (2) http://leica-geosystems.com/products/gnss-systems/ smart-antennas/leica-viva-gs14 (Leica Viva GS14 - GNSS Smart Antenna), (3) http://leicatotalstation.org/tag/ctr16/ (Leica CRT16 Bluetooth Cap, last access: 21 October 2020) and (4) http://leicatotalstation.org/tag/grz121/ (Leica GRZ121 360 Reflector PRO Surveying Prism, last access: 20 October 2020).

In 2017, a piece of land required changes for installation of tower 20/tse04. The topographic survey of that region was carried out (Alves, 2018) and incorporated in the lidar-based terrain model of March 2015. This survey was performed by Spectra Physics (SP60 GNNS receiver and data collector T41 with Survey Pro software) equipment and software by Sierrasoft (PROST Premium/Topko Standart, Version 14.3).

\section{Terrain model}

\subsection{Lidar point cloud processing}

The lidar data was classified in four data type classes (ground, vegetation, unassigned and noise), stored in LAS file format, and then post-processed with tools pertaining to the LAStools ${ }^{\circledR}$ software suite (LAStools, 2019) in three stages (Fig. 2).

Stage 1 was concerned with the extraction of the lidar raw data. The ground-class point cloud had irregular spacing (Fig. 1a), with lower point density in regions of vegetation clumping or non-overlapping scans. Some small, distinctive areas were found to be devoid of ground points due to watersheds and lidar reading or classification errors.

Stage 2 involved the reclassification of abnormal data. A first procedure was used to reclassify a particular area of noise-classified points into the ground or vegetation classes, which would otherwise be void of ground points. Points with excessive $(>700 \mathrm{~m})$ or negative elevations above sea level (a.s.l.) were removed during this stage. Isolated points above or below the more spatially dense point cloud, classified as ground or vegetation, were identified and removed using the lasnoise tool (LAStools, 2019).

In Stage 3, a triangulated irregular network (TIN), based on the Delaunay triangulation, was obtained for the groundclassified points. The DTM was obtained by interpolating the heights into a regular mesh with a resolution of $2 \mathrm{~m} \times 2 \mathrm{~m}$, the highest horizontal resolution of the terrain elevation within the Perdigão site.

\subsubsection{Buildings}

It is not clear whether a DTM should comprise buildings and other human-made artefacts that are usually part of digital surface models (DSMs). In the context of the present study, buildings are long-standing structures as a terrain feature, and we saw no reason for buildings to not be part of the DTM. The houses, in Fig. 1b, are family houses of about $15 \mathrm{~m} \times 15 \mathrm{~m}$ and $5 \mathrm{~m}$ height that will show on the finest mesh only and as a point elevation. Unless there are a few neighbouring buildings, the ability to resolve isolated houses is limited. 

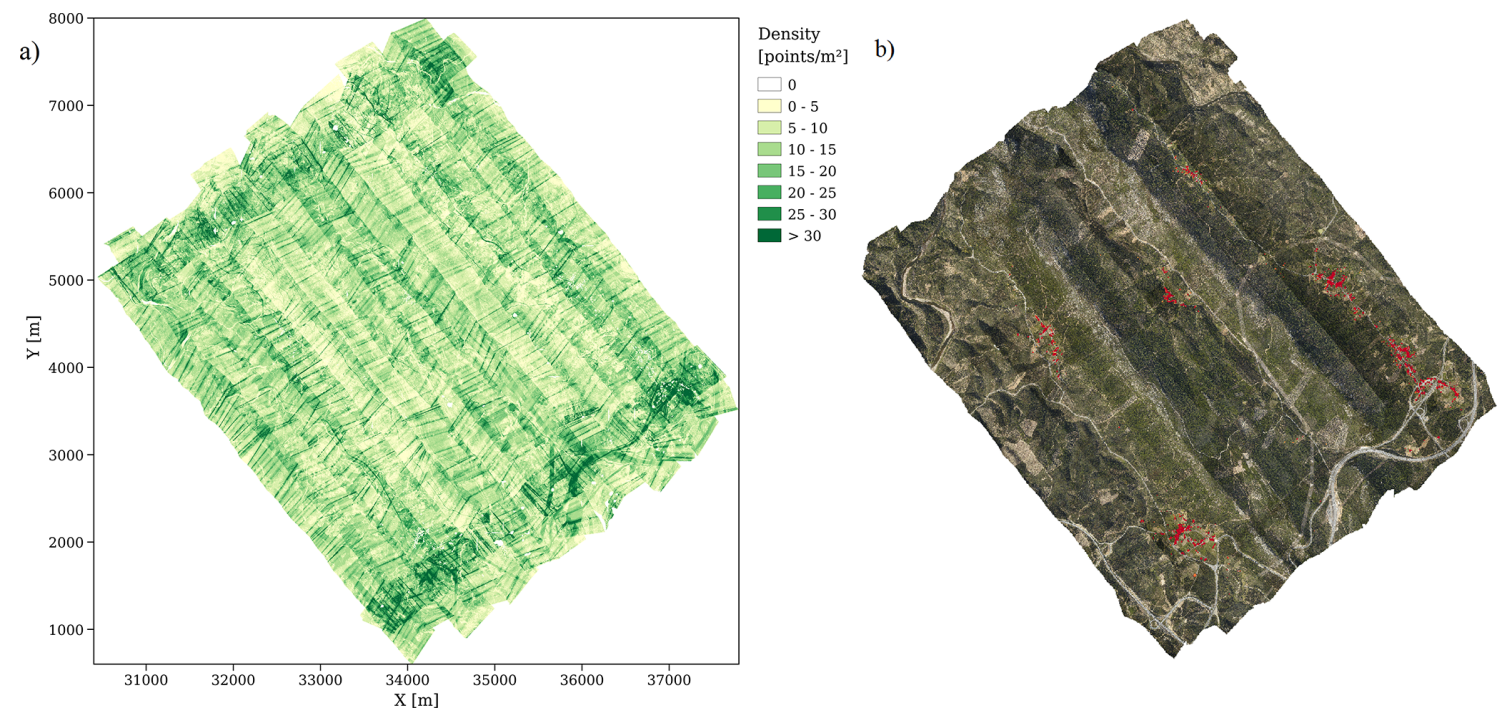

Figure 1. Lidar aerial survey and orthophoto: (a) ground-class point distribution; (b) orthophoto (houses in red).
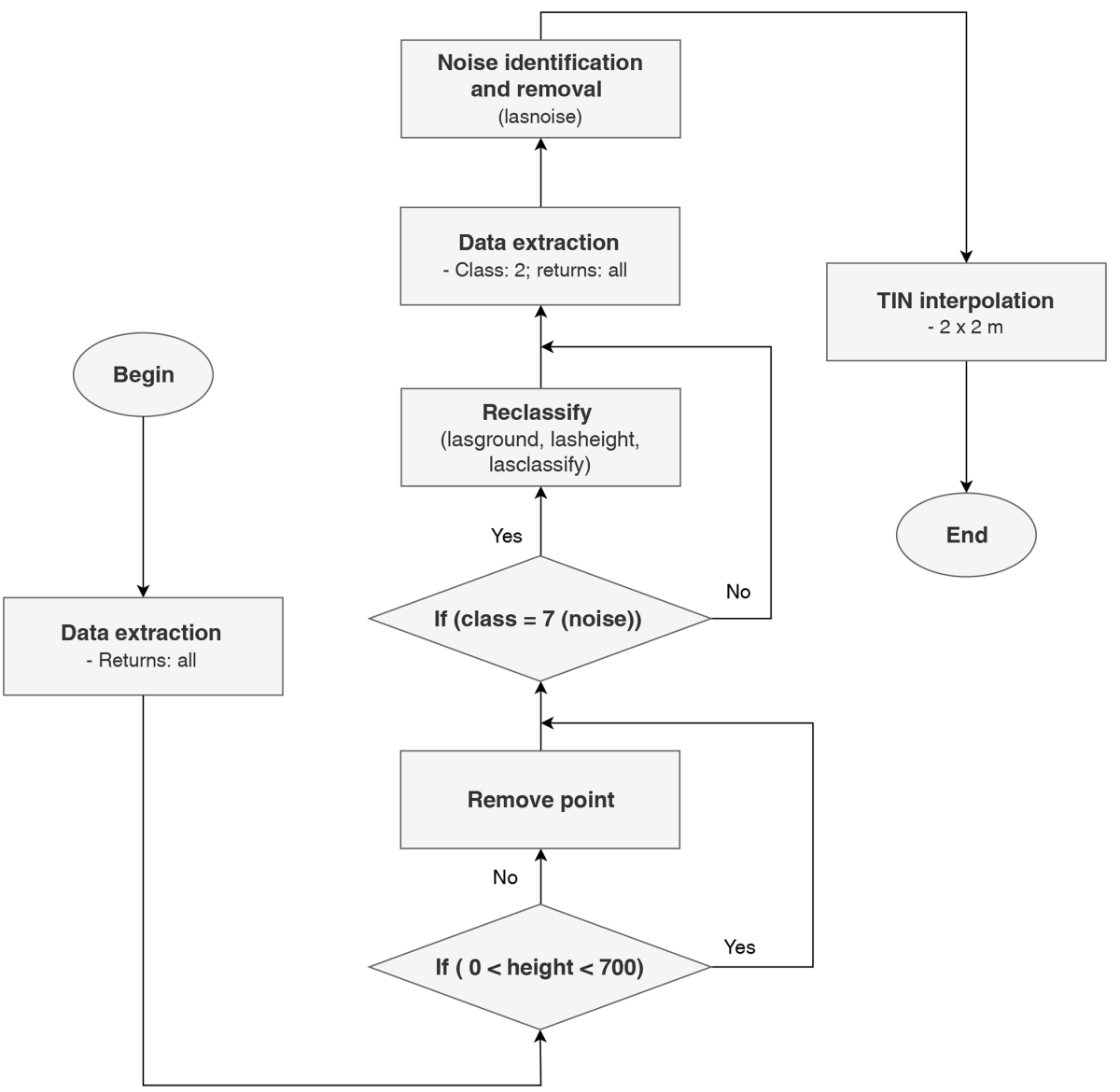

Figure 2. Workflow diagram for producing the terrain map using LAStools@. 
The first task, to include the building data in the DTM, embraced the digitalization of all buildings from the orthophotos. This process was needed to retain the building polygons as close as possible to their exact shape and location. The second task involved the extraction of unassigned data points, which included buildings and adjacent vegetation among other structures that fell within the polygons. These points were reclassified using the lasclassify tool (LAStools, 2019) to further remove adjacent and overhanging vegetation, and the resulting building-class points were converted to the ground class. The third and final stage comprised the generation of a TIN from the new ground point cloud followed by interpolation (blast 2 dem tool; LAStools, 2019) of the heights to a regular mesh with a resolution of $2 \mathrm{~m} \times 2 \mathrm{~m}$.

Calculations including the building data showed minor or no visible flow changes and were discarded. Nevertheless, for future use, two DTM versions, with and without buildings, are made available (Palma et al., 2020e).

\subsection{Two-dimensionality and main geometrical parameters}

One of the reasons why Perdigão was selected was its geometry, namely the parallelism between the two ridges and their large length relative to the width, bringing the orography close to two-dimensionality.

\subsubsection{Area of interest (AOI), reference lines and locations}

For scaling and dimensional analysis, the main geometrical parameters of the Perdigão site were determined, and the area of interest (AOI) was defined (Fig. 3 and Table 1): a rectangular shape of approximately $3 \mathrm{~km} \times 4 \mathrm{~km}$, with the lower left corner at $4394131 \mathrm{~N}, 608589 \mathrm{E}$ and aligned with the centreline $\left(\ell_{C} ; \mathrm{SE}-\mathrm{NW}\right.$ direction, $\left.135^{\circ}\right)$. This area, centred near station 131, included the SW and the NE ridge, the valley, and the location of most of the instrumentation deployed in Perdigão. Note that the coordinate system was converted from ETRS89 PT-TM06 (original source) to ED50 UTM29 and is used throughout the document as eastings and northings. Station number (No.) and code are given as on the Perdigão web site (https://perdigao.fe.up.pt, last access: 20 October 2020).

\subsubsection{Terrain profile and slope}

The terrain profile (Fig. 4) is not uniform along the valley, which becomes narrower and deeper along the SE-NW direction. For instance, the NW ridge height relative to a reference height $\left(h_{\text {ref }}\right.$; the mean height of the surrounding terrain in a $20 \mathrm{~km} \times 20 \mathrm{~km}$ area) equal to $250 \mathrm{~m}$ a.s.l. varies between 201.1 and $251.4 \mathrm{~m}$, and the distance between ridges is 1358.0 and $1480.0 \mathrm{~m}$ on transects A and D (Table 2).

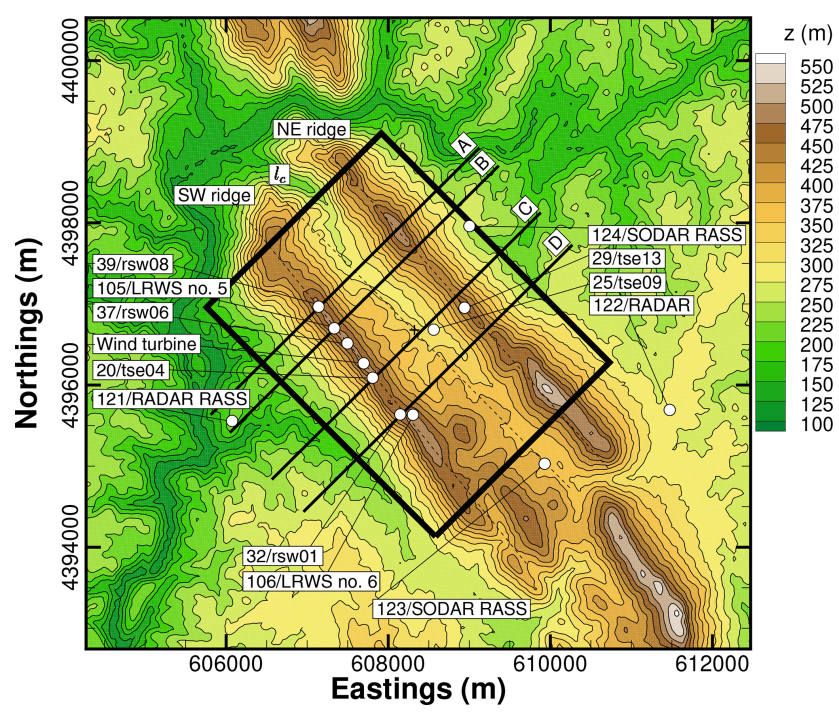

Figure 3. Area of interest and transects (ED50 UTM 29N).

Table 1. Reference points as in Fig. 3 (ED50 UTM 29N).

\begin{tabular}{llccc}
\hline No. & Type/code & $\begin{array}{c}\text { Eastings } \\
(\mathrm{m})\end{array}$ & $\begin{array}{c}\text { Northings } \\
(\mathrm{m})\end{array}$ & $\begin{array}{c}\text { Elevation } \\
(\mathrm{m})\end{array}$ \\
\hline & Wind turbine & 607697 & 4396268 & 484.0 \\
20 & 20/tse04 & 607808 & 4396090 & 473.0 \\
25 & 25/tse09 & 608561 & 4396683 & 305.3 \\
29 & 29/rsw01 & 608939 & 4396953 & 452.9 \\
32 & 32/rsw01 & 608149 & 4395638 & 472.1 \\
37 & 37/rsw06 & 607498 & 4396514 & 482.5 \\
39 & 39/rsw08 & 607140 & 4396966 & 488.9 \\
105 & LRWS \#5 & 607335 & 4396701 & 485.9 \\
106 & LRWS \#6 & 608307 & 4395634 & 486.3 \\
121 & RADAR/RASS & 606074 & 4395558 & 223.7 \\
122 & RADAR & 611474 & 4395697 & 288.6 \\
123 & SODAR/RASS & 609931 & 4395029 & 361.9 \\
124 & SODAR/RASS & 609003 & 4397960 & 258.4 \\
\hline
\end{tabular}

Apart from $\ell_{C}$, six additional lines were defined: $\ell_{\mathrm{SW}}$ and $\ell_{\mathrm{NE}}$ along the $\mathrm{SW}$ and the NE ridges and $\mathrm{A}, \mathrm{B}, \mathrm{C}$ and $\mathrm{D}$ perpendicular to the ridges ( $\mathrm{SW}-\mathrm{NE}$ direction, $225^{\circ}$ ) and related to four main transects - A and D, which delimit the northernmost (station 39) and southernmost (station 32) locations of the great majority of the instrumentation, and transects B and $\mathrm{C}$, which delimit a narrower region, determined by locations of stations 105/LRWS\#5 and 20/tse04.

Other geometric variables (Fig. 4) are the height of ridges ( $h_{\mathrm{SW}}$ and $h_{\mathrm{NE}}$ ) and the valley $\left(h_{\mathrm{val}}\right)$ relative to the reference height $\left(h_{\mathrm{ref}}\right)$, the half-widths of the ridges $\left(l_{\mathrm{SWw}}, l_{\mathrm{SWe}}, l_{\mathrm{NEw}}\right.$ and $\left.l_{\mathrm{NEe}}\right)$ at half-height $\left(h_{\mathrm{SW}} / 2\right.$ and $\left.h_{\mathrm{NE}} / 2\right)$, and the distance between ridges $\ell$.

The ridges' orientation was determined by a linear regression of two $z$ maxima for each $j$ (mesh oriented with a SW$\mathrm{NE}$ direction) on a $20 \mathrm{~m}$ grid between transects $\mathrm{A}$ and $\mathrm{D}$ 


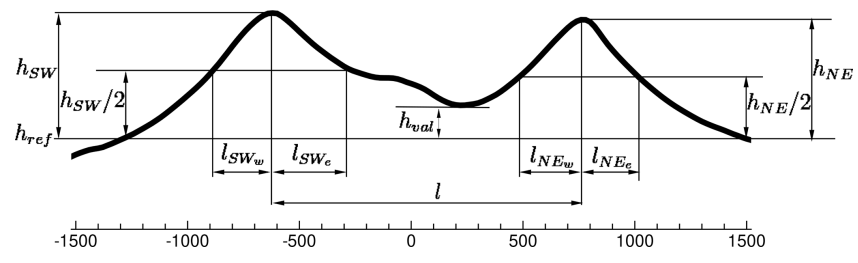

Figure 4. Terrain profile: geometrical parameters.

Table 2. Main geometric variables of transects A, B, C and D (slope $S$ in degrees, ${ }^{\circ}$, and length and elevation $\ell$ and $h$ in metres; $h_{\text {ref }}=$ 250 m a.s.1.).

\begin{tabular}{lrrrrr}
\hline & $\mathrm{A}$ & $\mathrm{B}$ & $\mathrm{C}$ & $\mathrm{D}$ & Average \\
\hline$h_{\mathrm{SW}}$ & 237.2 & 237.3 & 228.3 & 222.0 & 231.2 \\
$h_{\mathrm{NE}}$ & 251.4 & 212.7 & 205.3 & 201.1 & 217.6 \\
$h_{\mathrm{val}}$ & 24.5 & 31.1 & 46.8 & 65.2 & 41.9 \\
$l_{\mathrm{SWw}}$ & 277.8 & 214.0 & 232.0 & 212.3 & 234.0 \\
$l_{\mathrm{SWe}}$ & 270.0 & 305.0 & 402.9 & 432.0 & 352.5 \\
$l_{\mathrm{NEW}}$ & 286.9 & 320.2 & 249.5 & 268.7 & 281.3 \\
$l_{\mathrm{NEe}}$ & 258.4 & 245.0 & 221.9 & 261.7 & 246.7 \\
$l$ & 1358.0 & 1384.0 & 1412.0 & 1480.0 & 1408.5 \\
$l_{\mathrm{SWw}}$ & 33.6 & 37.5 & 36.8 & 40.0 & 37.0 \\
$S_{\mathrm{SWe}}$ & -45.1 & -29.6 & -22.7 & -21.1 & -29.6 \\
$S_{\mathrm{NEw}}$ & 30.7 & 25.7 & 27.8 & 25.7 & 27.5 \\
$S_{\mathrm{NEe}}$ & -35.7 & -30.1 & -30.7 & -24.1 & -30.1 \\
\hline
\end{tabular}

$(\approx 1650 \mathrm{~m})$ and between transects $\mathrm{B}$ and $\mathrm{C}(\approx 530 \mathrm{~m})$. The deviations from parallelism are $4.3^{\circ}$ if restricted to the region between $\mathrm{A}$ and $\mathrm{D}$. Between transects $\mathrm{B}$ and $\mathrm{C}$, where the core of the instrumentation was, the ridges were parallel within $2.8^{\circ}$, i.e. 139.1 and $136.3^{\circ}$ in the case of SW and NE ridges. The slope $\left(S=\left|\operatorname{atan}\left(h_{\mathrm{SW}, \mathrm{NE}} / 2\right)\right| / \ell_{\mathrm{SW}, \mathrm{NE}}\right)$, also on a $20 \mathrm{~m}$ grid, varies between 21.08 and $45.09^{\circ}$, always above the threshold for flow separation under neutral conditions (Wood, 1995).

\section{Digital terrain model: results and discussion}

The terrain elevation and slope are the two main terrain attributes for classification of terrain complexity and the ones to replicate accurately by terrain models. In this section, three DTMs of the Perdigão site are analysed within the AOI by comparing terrain elevation and slope on meshes based on these terrain models, with the terrain elevation and slope measured by the lidar aerial survey data within the AOI.

The three DTMs (Fig. 5 and Sect. 4.4) were the following: (1) ALS, the area sampled by lidar with a $2 \mathrm{~m}$ resolution; (2) military (Mil), the Portuguese Army cartography around Perdigão, $10 \mathrm{~m}$ horizontal resolution (available from the Portuguese Army Geospatial Information Centre; CIGeoE Centro de Informação Geoespacial do Exército, https://www.igeoe.pt (last access: 20 October 2020); a total of eight sheets - numbers 290.4, 291.3, 302.2, 302.4, 303.1,

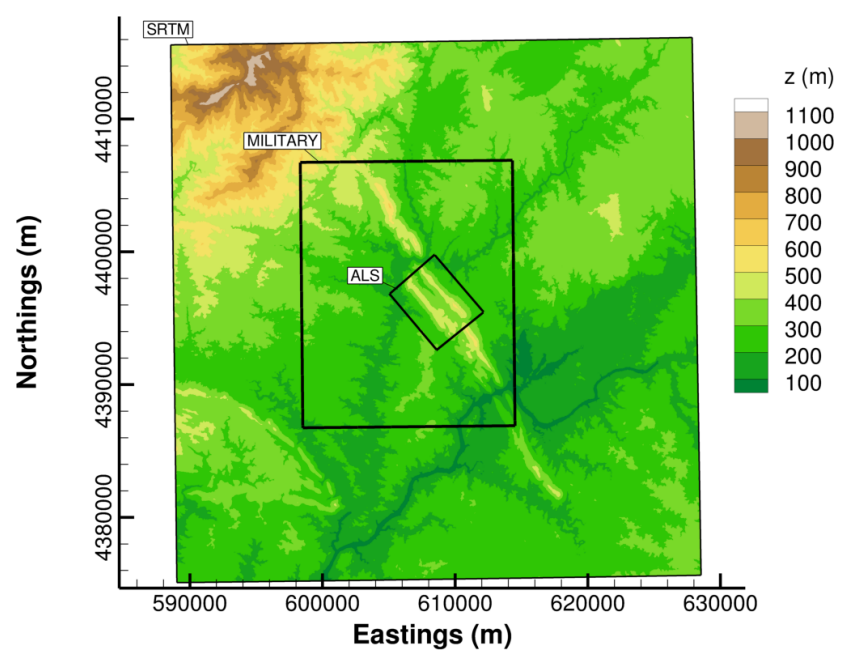

Figure 5. Total area comprised of SRTM, military and airborne data.

303.3, 313.2 and 314.1 - at a scale equal to $1: 25000$ ); and (3) SRTM, with a resolution of about $27 \mathrm{~m} \times 31 \mathrm{~m}$. Information on availability of these data can be found in Palma et al. (2020e) and in the data availability section at the end of the present study.

Because the ALS was the highest-resolution map and the most accurate representation of the terrain in Perdigão, it was the one against which the accuracy of alternative terrain data sources was evaluated.

Concerning the terrestrial surveys in 2017 and 2018 (Sect. 2.2), a sample of those measurements confirmed the high quality of lidar airborne measurements. The survey carried out in 2018 showed that the terrain change due to installation of tower 20 yielded alteration of the terrain that was not significant (less than $1 \mathrm{~m}$ ).

\subsection{Mesh generation}

For comparison of terrain attributes, elevation and slope, regularly spaced meshes of 80,40, 20 and $10 \mathrm{~m}$ (sizes $n_{i} \times n j$ of $39 \times 51,77 \times 101,153 \times 201$ and $305 \times 401$, respectively) were generated within the AOI. The resampling procedure was similar to Deng et al. (2007); i.e. one out of two points was retained to assure that every point in the coarser resolutions existed in the finer ones. Coarser meshes are resampled versions of the $2 \mathrm{~m}$ resolution mesh, obtained by removing additional nodes.

\subsection{Elevation at five reference points}

Five points (Table 1) were selected for DTM comparison: towers $20 /$ tse $04,25 /$ tse 09 and 29/tse 13 - the three $100 \mathrm{~m}$ meteorological towers, comprising a transect aligned with the dominant wind direction - tower 37/rsw06, and the wind turbine location along the SW ridge. 
Table 3. Maxima and minima terrain elevation, based on SRTM, Mil and ALS data.

\begin{tabular}{lrrrrrrrr}
\hline & \multicolumn{3}{c}{$z_{\text {Max }}(\mathrm{m})$} & & \multicolumn{3}{c}{$z_{\text {Min }}(\mathrm{m})$} \\
\cline { 2 - 4 } \cline { 7 - 9 } Mesh & SRTM & Mil & ALS & & SRTM & Mil & ALS \\
\hline 80 & 530.2 & 538.4 & 537.3 & & 165.0 & 159.4 & 157.0 \\
40 & 530.2 & 538.4 & 537.9 & & 165.0 & 159.4 & 157.0 \\
20 & 531.1 & 540.0 & 539.4 & & 165.0 & 158.8 & 156.8 \\
10 & 531.4 & 540.5 & 540.8 & & 165.0 & 158.8 & 156.8 \\
2 & - & - & 541.1 & & - & - & 156.8 \\
\hline
\end{tabular}

Table 4. Maxima and minima slope in the $x$ (SW-NE, 225 $5^{\circ}$ direction, based on SRTM, Mil and ALS terrain data.

\begin{tabular}{lrrrrrrrr}
\hline & \multicolumn{3}{c}{$S_{\text {Max }}\left(^{\circ}\right)$} & & \multicolumn{3}{c}{$S_{\text {Min }}\left(^{\circ}\right)$} \\
\cline { 2 - 4 } \cline { 6 - 8 } Mesh & SRTM & Mil & ALS & & SRTM & Mil & ALS \\
\hline 80 & 39.00 & 38.27 & 37.31 & & -36.11 & -37.99 & -37.33 \\
40 & 41.61 & 43.10 & 44.24 & & -38.64 & -47.61 & -51.74 \\
20 & 44.65 & 49.36 & 55.85 & & -47.18 & -55.19 & -59.31 \\
10 & 47.86 & 51.74 & 64.76 & & -49.02 & -61.31 & -67.81 \\
2 & - & - & 75.91 & & - & - & -81.13 \\
\hline
\end{tabular}

Figure 6 shows the absolute error $\left(z_{\text {error }}=z 80,40,20,10-\right.$ $z_{2}$ ), difference between the elevation at a given mesh and DTM source with respect to the terrain elevation on the reference mesh $\left(\mathrm{ALS}_{2}\right)$. In the case of SRTM-based meshes (Fig. 6a), the error tends to a plateau at resolutions equal to $40 \mathrm{~m}$. Similar behaviour is found in the case of the Mil database (Fig. 6b) but at $20 \mathrm{~m}$ resolution; 20 and $10 \mathrm{~m}$ meshes increase the error at 20/tse 04 , and meshes at higher resolution than the uncertainty of this database must be avoided. Contrary to the SRTM and Mil, when using ALS (Fig. 6c) with mesh refinement there is a noticeable error reduction at all five points.

\subsection{Elevation and slope in the area of interest (AOI)}

As the DTM quality increased from the SRTM to Mil and ALS, the maximum terrain elevation $\left(z_{\mathrm{Max}}\right)$ also increased, from 530.2 to 540.5 and $540.8 \mathrm{~m}$, and the minimum $\left(z_{\text {Min }}\right)$ decreased from 165.0 to 158.8 and $156.8 \mathrm{~m}$ (Table 3). Maxima and minima terrain elevations are set by the DTM source; maxima and minima are similar for a given DTM regardless of the grid size, which was a consequence of the procedure for mesh refinement. The $10 \mathrm{~m}$ difference between SRTM and the ALS values is consistent with the RMSE of the SRTM, equal to $6.2 \mathrm{~m}$ for Eurasia (Table 1, Farr et al., 2007), and also with the conclusions by DeWitt et al. (2015).

The error distribution (Figs. 8 and 10a) shows an overprediction of the terrain elevation along the valley and an underprediction along the ridges, with both much reduced between the 80 and the $40 \mathrm{~m}$ resolution meshes, with the latter showing a mostly uniform error distribution of around $1 \mathrm{~m}$ (Fig. 8b).
The RMSE error (Fig. 7) over the whole AOI is consistent with the elevation error and the inherent uncertainty of every DTM source; with mesh refinement every DTM tends to its resolution level. The minimum RMSEs of the SRTM, Mil and ALS are 7.43, 4.66 and $0.61 \mathrm{~m}$ at resolutions of $10 \mathrm{~m}$.

The maximum slope $\left(55.85\right.$ and $64.76^{\circ}$ ) was about $50 \%$ higher on 20 and $10 \mathrm{~m}$ meshes compared with the coarser resolution (37.31 and $44.24^{\circ}$ meshes, 80 and $40 \mathrm{~m}$; Table 4 ). The negative slope increased from $-37.33^{\circ}$ to $-67.81^{\circ}$ as the resolution increased from 80 to $10 \mathrm{~m}$. The histogram of the slope in the $x\left(\mathrm{SW}-\mathrm{NE}, 225^{\circ}\right)$ direction (Silva, 2018) shifted to the right as the content at low slopes decreases, and more and more higher slope locations were resolved. Because the ridges are quasi-two-dimensional, the $y$ (SE-NW, $135^{\circ}$ ) direction slope was residual (Silva, 2018) compared to the $x$ direction slope (Fig. 9) and is not shown here.

The larger errors occurred at locations of higher slope (Fig. 10), and these are the locations where the grid refinement was also the most effective in reducing the elevation error. For instance, errors equal to 11.5 and $-15.8 \mathrm{~m}$ (at $x=-720 \mathrm{~m}$ and $x=766 \mathrm{~m}$ ) on an $80 \mathrm{~m}$ mesh were reduced to 7.5 and $-2.5 \mathrm{~m}$ on a $40 \mathrm{~m}$ mesh.

\subsection{Spectra analysis}

Spectra of terrain elevation show the ALS resolution 1 order of magnitude higher compared to SRTM data (Fig. 11). The figure also displays two scaling ranges, typical of global topographies (e.g. Nikora and Goring, 2004), with exponents equal to $-7 / 4$ and $-11 / 3$.

As expected, there is an increase in resolved spectral range with mesh refinement and an overlap between meshes with ALS data. In the case of SRTM- and Mil-based meshes (Figs. 11a and b), linear refinements (20 and $10 \mathrm{~m}$ meshes) cannot replicate the decay for higher frequencies and overcome the inherent resolution of the original data. Mesh quality was as good as the terrain data source. Only meshes based on the ALS (Fig. 11c) have the ability to reproduce accurately the high-frequency range $\left(10^{-1} \mathrm{rad} \mathrm{m}^{-1}<k<\right.$ $1 \mathrm{rad} \mathrm{m}^{-1}$ ). The SRTM is restricted to around $30 \mathrm{~m}$ resolution, and meshes $20 \mathrm{~m} \times 20 \mathrm{~m}$ and $10 \mathrm{~m} \times 10 \mathrm{~m}$, with identical $z_{\text {Max }}$ and $z_{\operatorname{Min}}(531$ and $165 \mathrm{~m}$ ), are unable to replicate the ALS measured values, $z_{\text {Max }}$ and $z_{\text {Min }}$ (Table 3 ). Grid refinement cannot go beyond the inherent resolution of the DTM.

\subsection{RIX (ruggedness index)}

The RIX (ruggedness index) is one of the major parameters in WAsP (Mortensen et al., 2004). It has the goal of quantifying the terrain complexity. The operational envelope of WAsP corresponds to a RIX value of $0 \%$. The ALS data shows a maximum of $23.7 \%$ and an overall higher value of RIX (average $15.22 \%$ ), while the SRTM reaches $19.7 \%$ (average $11.6 \%$ ). Lower-resolution terrain data underestimate the terrain complexity. 
(a)

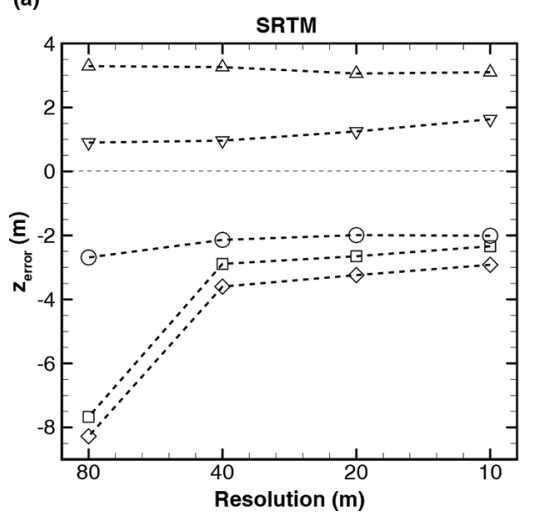

(b)

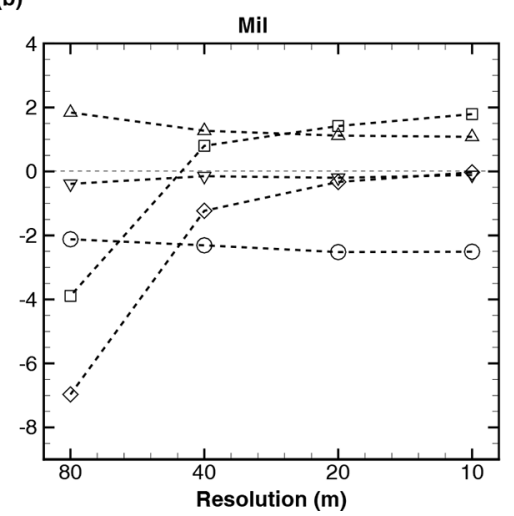

(c)

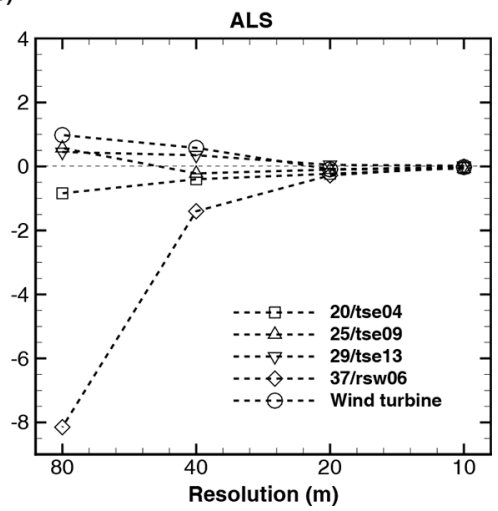

Figure 6. Impact of mesh resolution on reference points: (a) SRTM, (b) Mil, (c) ALS.

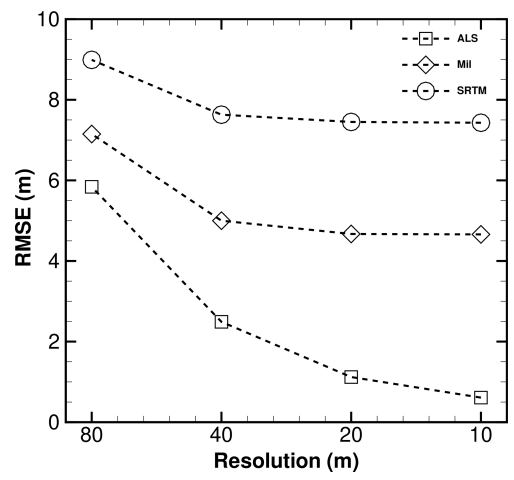

Figure 7. Impact of mesh resolution on RMSE.

\section{Flow modelling}

In this section, the results of computational runs on different meshes are discussed. A set of experimental data (UCAR/NCAR-EOL, 2019; $30 \mathrm{~min}$ averaged) on 4 May 2017, 22:09-22:39 UTM, is also included. This was the day and the time when the assumption of conditions of stationarity based on measurements at tower 20/tse04 were valid according to Carvalho (2019), and the flow was nonstratified based on a bulk Richardson number $\left(R_{\mathrm{B}}\right)$ equal to $-0.03$

$R_{\mathrm{B}}=\frac{g\left(\bar{\theta}_{100}-\bar{\theta}_{2}\right) \Delta z}{\bar{\theta}_{100}\left[\left(U_{100}\right)^{2}+\left(V_{100}\right)^{2}\right]}$,

where $\bar{\theta}_{100}$ and $\bar{\theta}_{2}$ are the mean potential temperature at $100 \mathrm{~m}$ and $2 \mathrm{~m}$ a.g.l. (above the ground level), $\Delta z=100 \mathrm{~m}$, and $U_{100}$ and $V_{100}$ are the mean horizontal components of the velocity vector also at $100 \mathrm{~m}$ a.g.l. The temperature obtained from measurement data was converted into potential temperature using the following approximation (Stull, 1988):

$\bar{\theta} \approx \bar{T}+\left(\frac{g}{c_{p}}\right) z$
The data set choice was conditioned by the computational flow model being used. Because computational results do not consider, for instance, surface cover heterogeneity, discrepancies are expected when compared with experimental data, which are included here for guidance only.

\subsection{Computational flow model}

The computational code VENTOS ${ }^{\circledR} / 2$ (cf., Castro et al., 2003; Palma et al., 2008), developed for atmospheric flows over complex terrain, was used in steady-state formulation. It solves the Reynolds-averaged Navier-Stokes set of equations for a turbulent flow $(k-\varepsilon$ model), with a terrain-following structured mesh, also allowing the simulation of forested terrain (Costa et al., 2006) and wind turbine wakes (Gomes et al., 2014; Gomes and Palma, 2016).

\subsubsection{Integration domain and boundary conditions}

The model topography (domain size: $19 \mathrm{~km} \times 18.8 \mathrm{~km}$ around the central location $4396621 \mathrm{~N}, 608250 \mathrm{E}$ ) was obtained by bilinear interpolation of terrain data. The positioning of the domain boundaries and their impact on flow variables were part of the work of Silva (2018).

At the inlet a log-law profile was set. To ensure an equilibrium shear stress, the $k$ profile decreases with the square of height above ground level. At the top of the domain a zero shear stress condition was used. The inlet profile's development is capped at the boundary layer's limit, all quantities being constant above that height. At the lateral boundaries a symmetry condition was applied.

The ground was modelled as a rough surface, a wall function, a log-law defining the velocity at the node closest to the ground, and the turbulence model quantities $k$ and $\varepsilon$. The values used in the computational model for $z_{0}$ (roughness length) and $u_{*}$ (friction velocity) were 0.1 (indicated by Wagner et al., 2019, as the roughness length near the double ridge area after conversion from the CORINE Land Cover classes) and 0.25 . These values were uniform for the whole domain. 
(a)

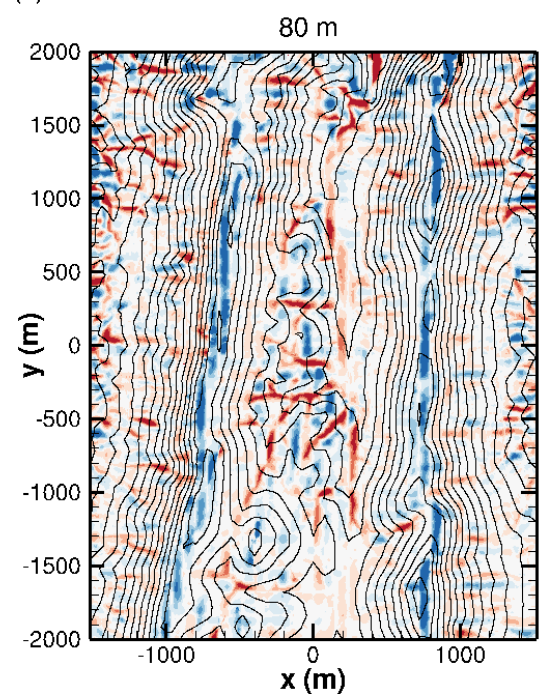

(b)

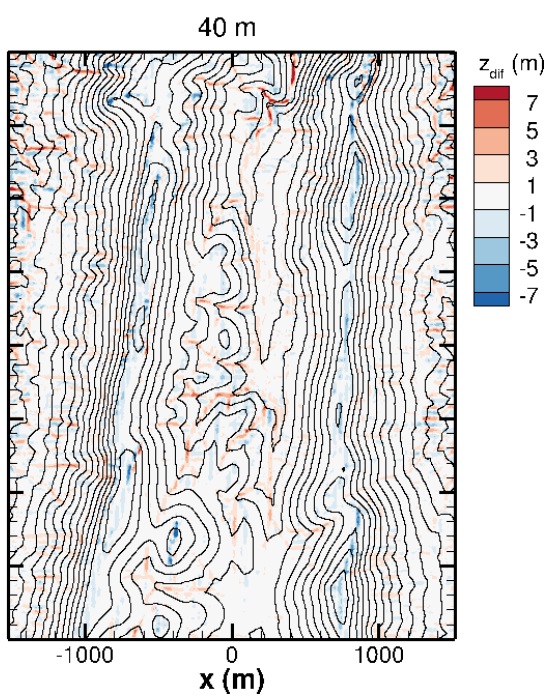

Figure 8. Elevation error of resampled meshes (ALS terrain data) over the AOI surface: (a) $80 \mathrm{~m}$ mesh, (b) $40 \mathrm{~m}$ mesh.

(a)

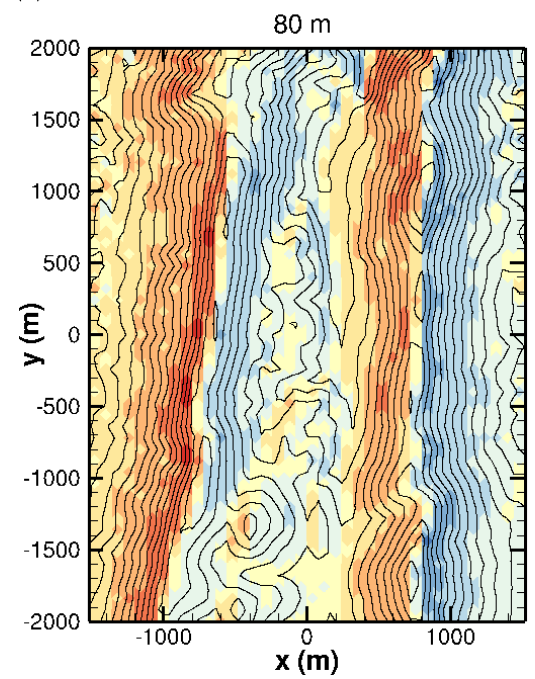

(b)

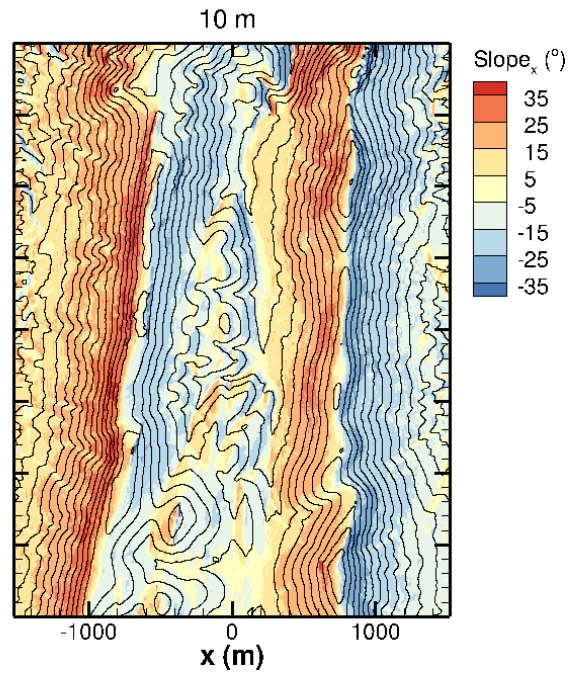

Figure 9. Slope in $x\left(\mathrm{SW}-\mathrm{NE}, 225^{\circ}\right)$ direction with different resolutions mapped on the AOI's surface (ALS terrain data): (a) $80 \mathrm{~m}$ mesh, (b) $10 \mathrm{~m}$ mesh.

The surface cover (forest patches and height) and its representation in the computational model (roughness length, leaf area index, use of a canopy model) are still a work in progress as the presence of eucalyptus and pine tree patches in the area are expected to have an impact on the flow. However, this would increase the number of variables influencing the flow results, masking the effects of the digital terrain model alone. See for instance the effects of forest resolution and wind orientation relative to the forest stands in the computational modelling of flow over forests in Costa et al. (2006).

\subsection{Computational meshes}

A total of 18 computational meshes (Table 5) were used. The central part of the domain $(4 \mathrm{~km} \times 6 \mathrm{~km}$, based on ALS and Mil terrain data) was resolved with uniform horizontal resolution $(20 \mathrm{~m} \times 20 \mathrm{~m}, 40 \mathrm{~m} \times 40 \mathrm{~m}$ and $80 \mathrm{~m} \times 80 \mathrm{~m})$, expanding towards the domain boundaries with factors $f_{x}$ and $f_{y}$ close to 1 , to minimize the discretization errors. The domain's height $(3000 \mathrm{~m})$ was discretized by 100 nodes $\left(N_{k}\right)$, with the first node $2 \mathrm{~m}$ above ground level and a grid expansion $f_{z}=1.0435$, yielding a maximum cell size $\left(\Delta_{z}\right)$ equal to $124 \mathrm{~m}$. For availability of meshes ALS.SW.\#\# and 
(a)

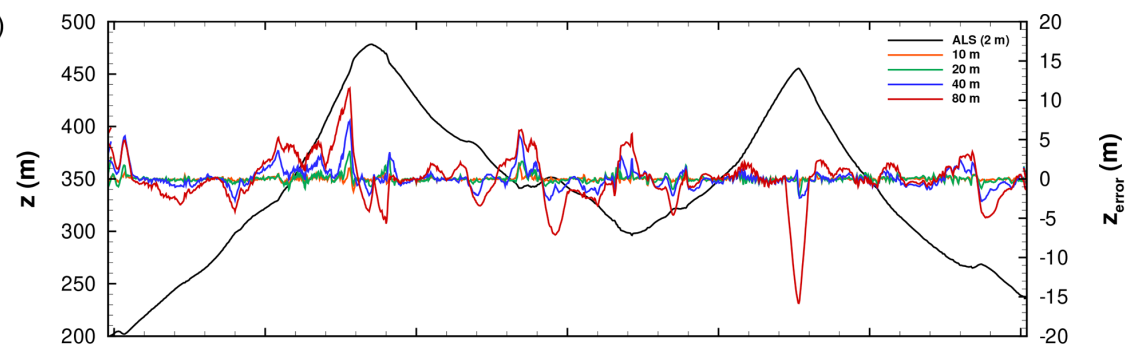

(b)

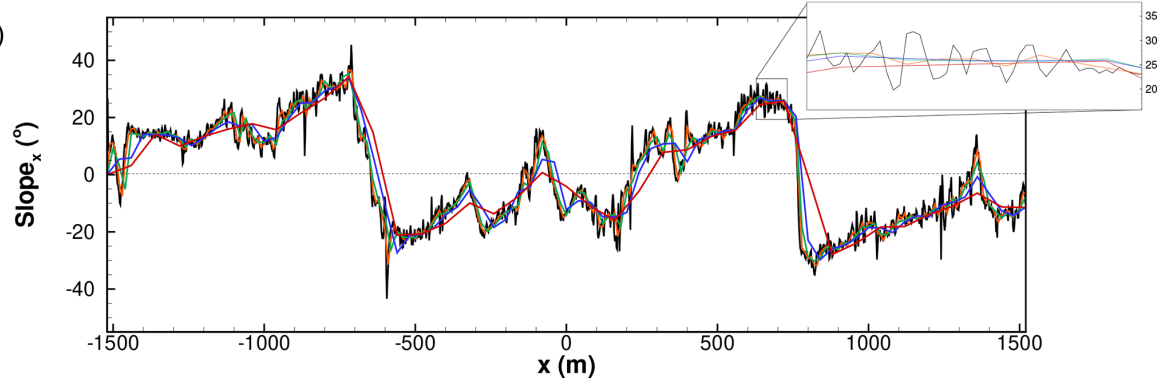

Figure 10. Terrain along transect C (see Fig. 3), ALS-based meshes: (a) terrain profile and elevation error, (b) slope in the $x$ direction.
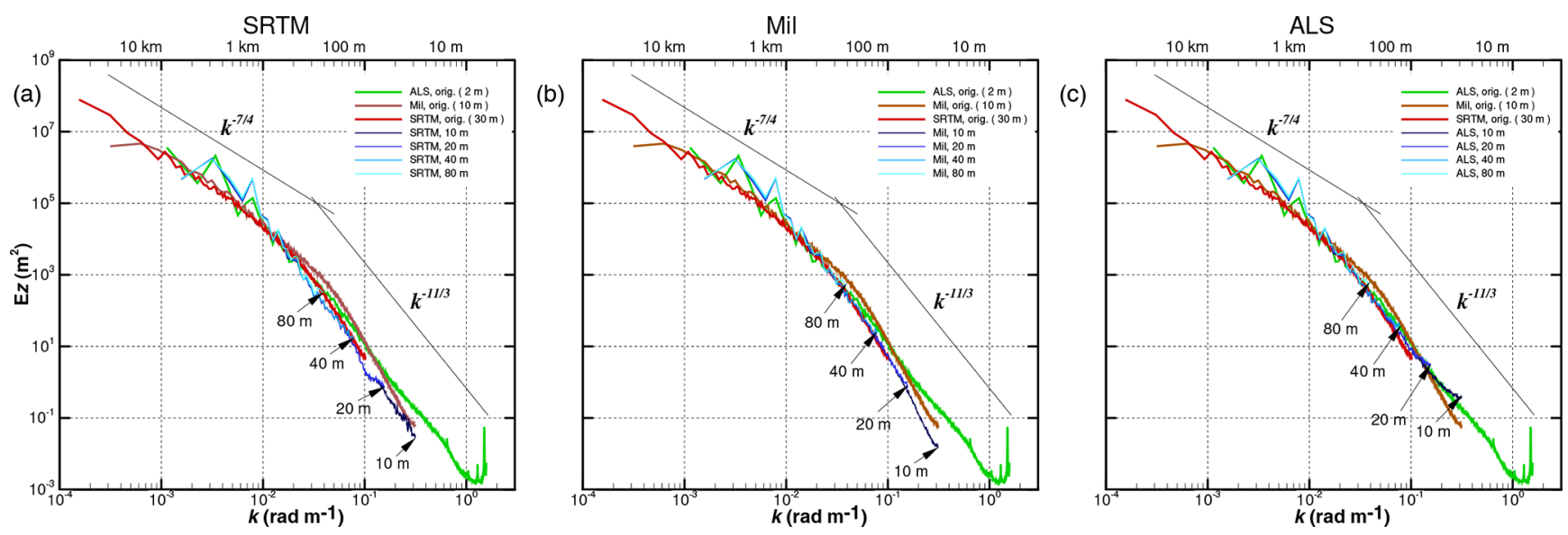

Figure 11. Spectra analysis for DTM and meshes: (a) SRTM, (b) Mil, (c) ALS.

ALS.NE.\#\#, see Palma et al. (2020e) and information in the data availability section at the end of this study.

A preliminary analysis showed that the flow variables had low sensitivity to the number of nodes in the vertical $\left(n_{k}\right)$ opposed to the height of the first node above ground level, which showed a significant impact, and is worthy of further studies.

Three types of meshes were used: the SRTM, with the whole domain based on the SRTM data; Mil, a combination of SRTM and military maps; and ALS, based on all three DTM sources (Fig. 5). A minimum of 8818 iterations and $3.87 \mathrm{~h}$ of computing time and, in the case of mesh Mil.NE.20, a maximum of 20033 iterations and 50 times more computing time were required. Number of iterations is a better indicator of the actual computing time since the value given here was influenced by the computer load at the time of the calculations.

\subsection{Flow pattern}

The flow modelling analysis was based on the flow patterns at two transects in the case of SW and NE winds (Figs. 12 and 13) and wind speed, wind direction and turbulent kinetic energy results for SW (Figs. 14-16).

As expected, the flow pattern (Figs. 12 and 13) is characterized by separated flow regions on the lee side of either ridge. The figures are coloured by the spanwise velocity component $(v)$, showing two different streams: up-valley on the lee side of the SW ridge and down-valley on the upwind side of the NE ridge (Fig. 12) and down-valley in the case of NE winds (Fig. 13). The ridge height increases with the grid reso- 
Table 5. Computational meshes $\left(\Delta z_{\mathrm{Min}}=2 \mathrm{~m}\right)$.

\begin{tabular}{|c|c|c|c|c|c|c|}
\hline & \multirow[t]{3}{*}{ Name } & \multicolumn{2}{|c|}{$\Delta_{x / y}$} & \multirow{3}{*}{$N_{i} \times N_{j}$} & \multirow{3}{*}{$\begin{array}{r}t_{\mathrm{CPU}} \\
(h)\end{array}$} & \multirow{3}{*}{$N_{\text {iter }}$} \\
\hline & & \multirow{2}{*}{$\frac{\min }{(\mathrm{m})}$} & \multirow{2}{*}{ Max } & & & \\
\hline & & & & & & \\
\hline 1 & SRTM.SW.80 & 80 & 478.6 & $120 \times 155$ & 6.27 & 8818 \\
\hline 2 & SRTM.SW.40 & 40 & 400.0 & $200 \times 270$ & 52.96 & 11557 \\
\hline 3 & SRTM.SW.20* & 20 & 414.0 & $320 \times 470$ & - & - \\
\hline 4 & Mil.SW.80 & 80 & 478.6 & $120 \times 155$ & 18.13 & 8906 \\
\hline 5 & Mil.SW.40 & 40 & 400.0 & $200 \times 270$ & 89.64 & 11040 \\
\hline 6 & Mil.SW.20 & 20 & 414.0 & $320 \times 470$ & 237.35 & 14095 \\
\hline 7 & ALS.SW.80 & 80 & 478.6 & $120 \times 155$ & 3.87 & 8898 \\
\hline 8 & ALS.SW.40 & 40 & 400.0 & $200 \times 270$ & 15.09 & 10996 \\
\hline 9 & ALS.SW.20 & 20 & 414.0 & $320 \times 470$ & 111.28 & 16606 \\
\hline 10 & SRTM.NE.80 & 80 & 478.6 & $120 \times 155$ & 19.92 & 9554 \\
\hline 11 & SRTM.NE.40 & 40 & 400.0 & $200 \times 270$ & 110.04 & 14227 \\
\hline 12 & SRTM.NE.20 & 20 & 414.0 & $320 \times 470$ & 242.57 & 15188 \\
\hline 13 & Mil.NE.80 & 80 & 478.6 & $120 \times 155$ & 28.43 & 9313 \\
\hline 14 & Mil.NE.40 & 40 & 400.0 & $200 \times 270$ & 101.90 & 13351 \\
\hline 15 & Mil.NE.20 & 20 & 414.0 & $320 \times 470$ & 191.38 & 20033 \\
\hline 16 & ALS.NE.80 & 80 & 478.6 & $120 \times 155$ & 3.74 & 9322 \\
\hline 17 & ALS.NE.40 & 40 & 400.0 & $200 \times 270$ & 93.49 & 11937 \\
\hline \multirow[t]{6}{*}{18} & ALS.NE.20 & 20 & 414.0 & $320 \times 470$ & 80.21 & 18634 \\
\hline & & & \multicolumn{3}{|c|}{ Expansion factors } & \\
\hline & \multicolumn{2}{|c|}{$\min \left(\Delta_{x / y}\right)$} & $f_{x}$ & $f_{y}$ & $f_{z}$ & \\
\hline & & 80 & 1.0524 & 1.0331 & 1.0435 & \\
\hline & & 40 & 1.0471 & 1.0299 & 1.0435 & \\
\hline & & 20 & 1.0518 & 1.0271 & 1.0435 & \\
\hline
\end{tabular}

* Did not meet residual criteria.

lution (see insets), and the detachment point moves to higher elevations, yielding longer and deeper separated flow regions (see for instance Fig. 13).

Menke et al. (2019), in their analysis of the experimental data, reported average length and depth equal to 697 and $157 \mathrm{~m}$ for both SW and NE wind directions and stratification levels based on the gradient Richardson number between -1 and 1; in the case of neutral flow, length and height equal to 807 and $192 \mathrm{~m}$ were reported for a $10 \mathrm{~min}$ period. The length and height of the separation zone, in Table 6, tend to increase with the grid refinement (with the exception of the SW winds when refining from 40 to $20 \mathrm{~m}$ resolution), predicting a recirculation region longer and narrower compared with the measurements.

\subsection{Southwesterly winds}

The wind speed, wind direction and turbulent kinetic energy profiles at towers 20/tse04, 25/tse09 and 29/tse13 (Figs. 14, 15 and 16) show a good agreement of the wind direction with the measurements, a poor agreement of the wind speed (underprediction) at all towers, and underprediction of the turbulent kinetic energy in the valley and at the NE ridge (towers
Table 6. Length and maximum depth of separation zone.

\begin{tabular}{lcr}
\hline & Length $(\mathrm{m})$ & Height $(\mathrm{m})$ \\
\hline \multicolumn{3}{l}{ Southwesterly winds } \\
\hline 80 & 1040.1 & 142.9 \\
40 & 1120.0 & 131.8 \\
20 & 1000.1 & 155.0 \\
\hline \multicolumn{3}{l}{ Northeasterly winds } \\
\hline 80 & 762.5 & 135.1 \\
40 & 1120.9 & 143.4 \\
20 & 1159.3 & 151.8 \\
\hline
\end{tabular}

25/tse09 and 29/tse13; Figs. 15c and 16c). A good agreement between computational and experimental results is not expected, mainly because of the uniform roughness length; the important issue is the sensitivity of the computational results to the different numerical meshes.

As an indicator of stationarity, the mean values of the experimental results over the $30 \mathrm{~min}$ period are plotted, showing the minima and maxima within that period as error bars. 


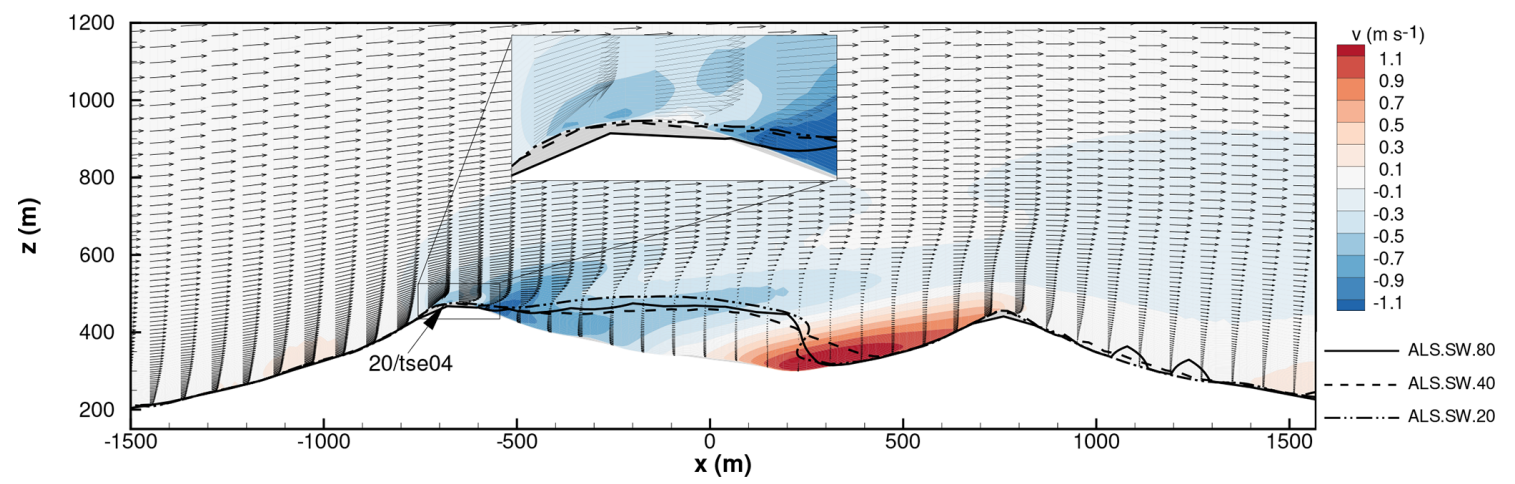

Figure 12. Impact of mesh resolution on separation zone in transect that crosses tower 20/tse04 in the case of SW winds.

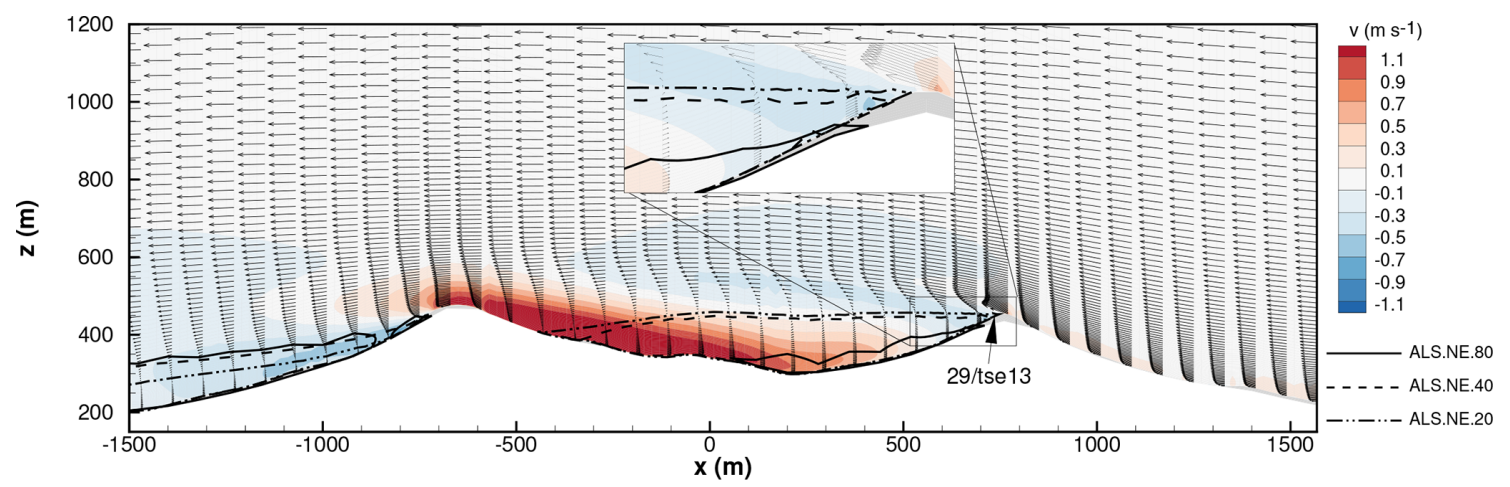

Figure 13. Impact of mesh resolution on separation zone in transect that crosses tower $29 /$ tse 13 in the case of NE winds.

Departure from stationarity condition reaches a higher magnitude in the valley (Fig. 15), given the location of tower $25 /$ tse 09 inside the recirculation zone. Unsteadiness is a wellknown characteristic of recirculation zones, and their prediction is very sensitive to spatial resolution (Castro et al., 2003) and terrain model as shown by Fig. 15b. The separated flow region, tower 25/tse09 (Fig. 15), is characterized by low wind speed and rotation of the wind with the distance above the ground. The wind speeds at $z_{\text {asl }}>100$ decrease as the mesh is refined, and the height of the recirculation zone increases (Table 6). The flow in the valley is aligned with the valley and therefore perpendicular to the ridges and the incoming wind. The predicted wind direction is in close agreement with the measurements, with the exception of 40 and $20 \mathrm{~m}$ meshes based on the Mil DTM.

As a whole, the flow results appear to be more sensitive to the resolution than to the DTM (see, for instance, Fig. 14a), with the results on 40 and $20 \mathrm{~m}$ meshes detached from results on the $80 \mathrm{~m}$ mesh. A resolution of at least $40 \mathrm{~m}$ is required.

The profiles (not shown) in the case of NE winds $\left(45^{\circ}\right)$ are similar to SW winds, apart from the situation being reversed, since in this case the first and second ridge are the NE and SW ridges.

Differences between the profiles and the reference profile $\mathrm{ALS}_{20}$ were measured in terms of RMSE (Tables 7, 8 and
9), which, in general, show a pattern similar to the slope (Table 4), where the RMSE decreases by either refining the mesh or, for a given mesh, moving from the SRTM to Miland ALS-based meshes. RMSE values at towers 20/tse04 and 29/tse13 (Tables 7 and 9) on the hills depend on the dominant wind directions, showing the effects of the valley flow on the downstream hill. The effect of calculations on $20 \mathrm{~m}$ mesh compared to those on $40 \mathrm{~m}$ mesh are less than the effect of calculations on $40 \mathrm{~m}$ mesh compared to those on $80 \mathrm{~m}$ mesh.

\section{Discussion and conclusions}

Meshes for computational modelling of flow over the Perdigão site were created based on three digital terrain models: high-resolution ( $2 \mathrm{~m}$ resolution) airborne lidar survey (ALS), military $(10 \mathrm{~m})$ and SRTM $(30 \mathrm{~m})$ data. The mesh appraisal was carried out in two ways: by their ability to replicate the two main terrain attributes, elevation and slope, and by their effect on the wind flow computational results (wind speed, wind direction and turbulence kinetic energy) at three locations.

Regarding the digital terrain models, the main conclusions were the following: 


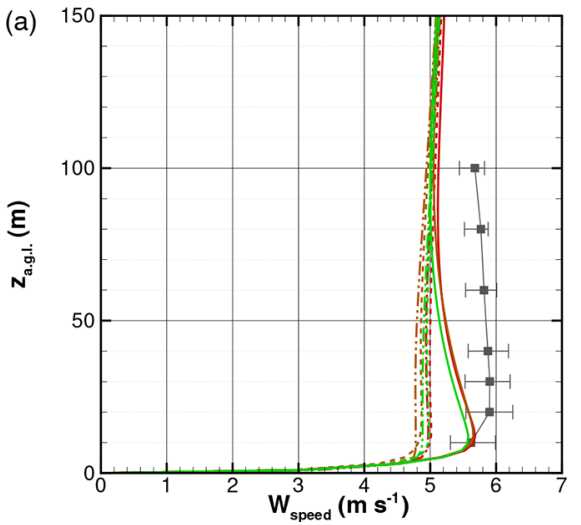

(b)

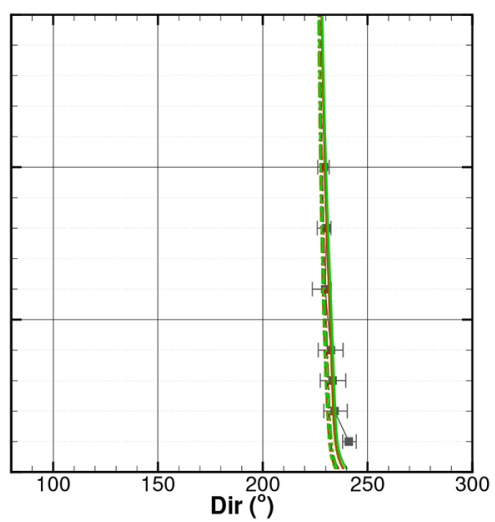

(c)

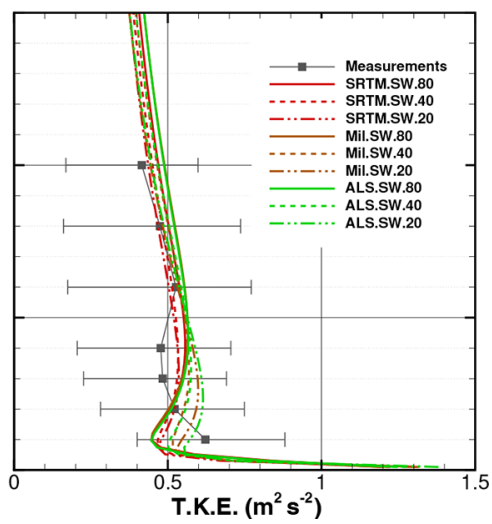

Figure 14. Simulation results and experimental data in tower 20/tse04 for SW winds: (a) wind speed, (b) wind direction, (c) turbulent kinetic energy.

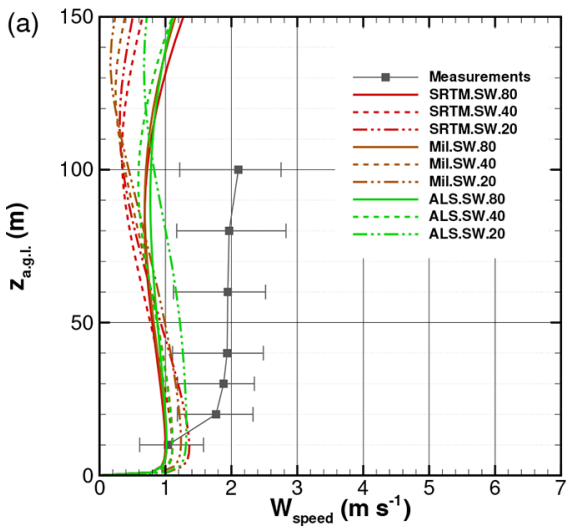

(b)

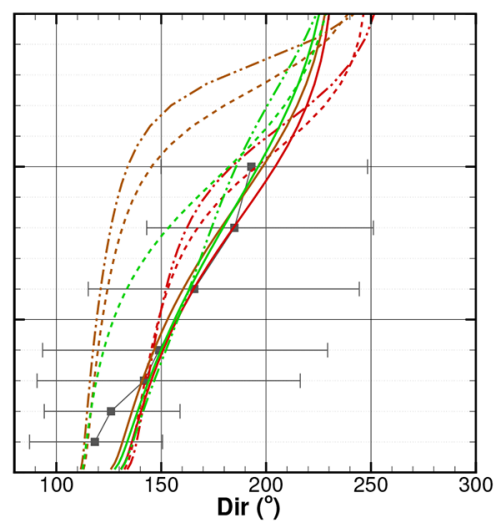

(c)

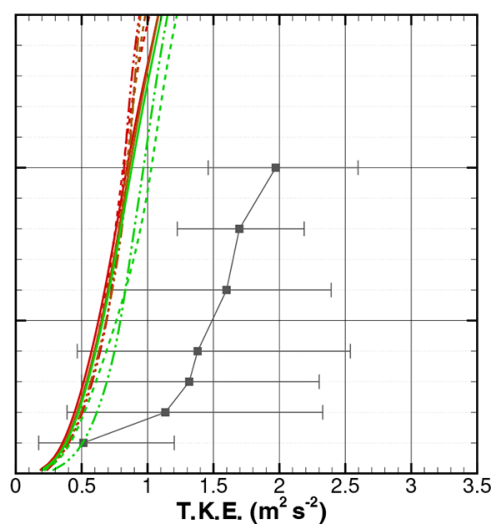

Figure 15. Simulation results and experimental data in tower 25/tse09 for SW winds: (a) wind speed, (b) wind direction, (c) turbulent kinetic energy.

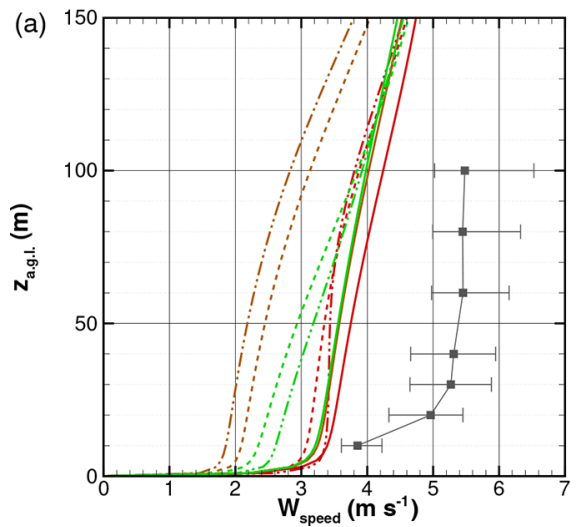

(b)

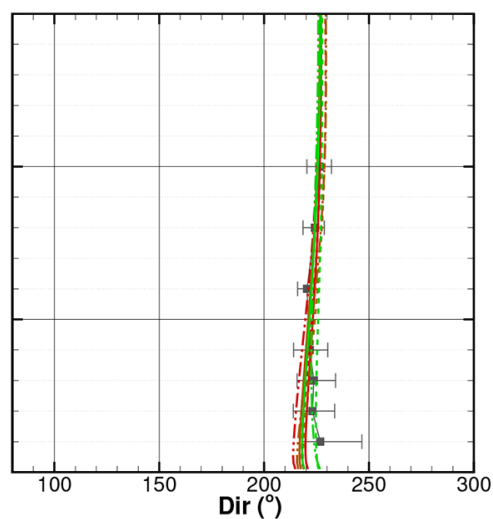

(c)

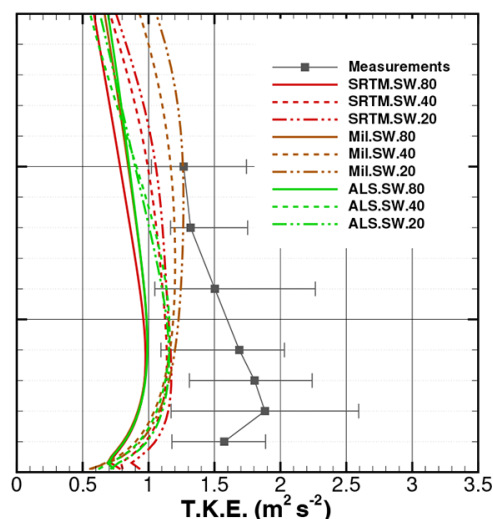

Figure 16. Simulation results and experimental data in tower 29/tse13 for SW winds: (a) wind speed, (b) wind direction, (c) turbulent kinetic energy. 
Table 7. RMSE of wind speed, wind direction and turbulent kinetic energy for tower 20/tse04.

\begin{tabular}{|c|c|c|c|c|c|c|c|c|c|}
\hline & \multicolumn{3}{|c|}{$W_{\text {speed }}\left(\mathrm{m} \mathrm{s}^{-1}\right)$} & \multicolumn{3}{|c|}{$\operatorname{Dir}\left(^{\circ}\right)$} & \multicolumn{3}{|c|}{ T.K.E $\left(\mathrm{m}^{2} \mathrm{~s}^{-2}\right)$} \\
\hline & SRTM & Mil & ALS & SRTM & Mil & ALS & SRTM & Mil & ALS \\
\hline \multicolumn{10}{|c|}{ Southwesterly winds } \\
\hline 80 & 0.83 & 0.81 & 0.68 & 4.60 & 4.65 & 6.28 & 0.13 & 0.14 & 0.13 \\
\hline 40 & 0.20 & 0.17 & 0.12 & 0.79 & 1.70 & 1.60 & 0.12 & 0.08 & 0.07 \\
\hline 20 & 0.09 & 0.21 & - & 0.71 & 1.80 & - & 0.11 & 0.03 & - \\
\hline \multicolumn{10}{|c|}{ Northeasterly winds } \\
\hline 80 & 1.28 & 2.53 & 2.43 & 16.80 & 16.49 & 14.90 & 0.78 & 1.01 & 1.04 \\
\hline 40 & 0.99 & 0.50 & 0.22 & 9.84 & 9.83 & 4.09 & 0.46 & 0.33 & 0.39 \\
\hline 20 & 0.18 & 0.30 & - & 5.04 & 2.74 & - & 0.06 & 0.08 & - \\
\hline
\end{tabular}

Table 8. RMSE of wind speed, wind direction and turbulent kinetic energy for tower 25/tse09.

\begin{tabular}{|c|c|c|c|c|c|c|c|c|c|}
\hline & \multicolumn{3}{|c|}{$W_{\text {speed }}\left(\mathrm{m} \mathrm{s}^{-1}\right)$} & \multicolumn{3}{|c|}{$\operatorname{Dir}\left({ }^{\circ}\right)$} & \multicolumn{3}{|c|}{ T.K.E $\left(\mathrm{m}^{2} \mathrm{~s}^{-2}\right)$} \\
\hline & SRTM & Mil & ALS & SRTM & Mil & ALS & SRTM & Mil & ALS \\
\hline \multicolumn{10}{|c|}{ Southwesterly winds } \\
\hline 80 & 0.87 & 0.77 & 0.69 & 26.67 & 20.10 & 14.81 & 0.33 & 0.29 & 0.26 \\
\hline 40 & 0.92 & 0.90 & 0.70 & 38.14 & 75.35 & 48.96 & 0.36 & 0.34 & 0.16 \\
\hline 20 & 0.81 & 0.84 & - & 37.03 & 92.73 & - & 0.36 & 0.32 & - \\
\hline \multicolumn{10}{|c|}{ Northeasterly winds } \\
\hline 80 & 2.82 & 3.67 & 3.54 & 157.07 & 158.04 & 153.56 & 0.25 & 0.49 & 0.49 \\
\hline 40 & 0.39 & 0.88 & 0.53 & 88.82 & 79.37 & 69.95 & 0.51 & 0.33 & 0.23 \\
\hline 20 & 0.19 & 0.17 & - & 40.61 & 43.20 & - & 0.22 & 0.15 & - \\
\hline
\end{tabular}

Table 9. RMSE of wind speed, wind direction and turbulent kinetic energy for tower 29/tse13.

\begin{tabular}{|c|c|c|c|c|c|c|c|c|c|}
\hline & \multicolumn{3}{|c|}{$W_{\text {speed }}\left(\mathrm{m} \mathrm{s}^{-1}\right)$} & \multicolumn{3}{|c|}{$\operatorname{Dir}\left({ }^{\circ}\right)$} & \multicolumn{3}{|c|}{ T.K.E $\left(\mathrm{m}^{2} \mathrm{~s}^{-2}\right)$} \\
\hline & SRTM & Mil & ALS & SRTM & Mil & ALS & SRTM & Mil & ALS \\
\hline \multicolumn{10}{|c|}{ Southwesterly winds } \\
\hline 80 & 1.19 & 0.82 & 0.77 & 4.87 & 7.16 & 5.92 & 0.33 & 0.28 & 0.27 \\
\hline 40 & 0.51 & 1.68 & 0.44 & 6.30 & 8.45 & 6.05 & 0.16 & 0.52 & 0.10 \\
\hline 20 & 0.83 & 2.33 & - & 10.40 & 10.03 & - & 0.28 & 0.70 & - \\
\hline \multicolumn{10}{|c|}{ Northeasterly winds } \\
\hline 80 & 0.44 & 0.49 & 0.44 & 16.15 & 17.73 & 16.79 & 0.13 & 0.15 & 0.13 \\
\hline 40 & 0.26 & 0.16 & 0.24 & 6.94 & 10.26 & 5.35 & 0.06 & 0.07 & 0.06 \\
\hline 20 & 0.18 & 0.09 & - & 2.98 & 4.66 & - & 0.04 & 0.03 & - \\
\hline
\end{tabular}

1. The SRTM data are not an accurate representation of the Perdigão site.

2. Only meshes based on the ALS have the ability to reproduce the smaller scales between 10 and $100 \mathrm{~m}$.

3. The ALS data yielded the lowest elevation errors: average RMSE around $5.8 \mathrm{~m}$ on $80 \mathrm{~m}$, decreasing to $0.6 \mathrm{~m}$ on $10 \mathrm{~m}$ mesh.
4. The RMSE for the SRTM does not go below $7.4 \mathrm{~m}$. A $40 \mathrm{~m}$ horizontal resolution based on the ALS data is enough to achieve an error below $1.4 \mathrm{~m}$ in five key locations and below $0.28 \mathrm{~m}$ using a $20 \mathrm{~m}$ mesh.

5. The maximum terrain slope was about 1.8 times higher $\left(-67.81^{\circ}\right)$ on a $20 \mathrm{~m}$ mesh resolution compared with an $80 \mathrm{~m}$ mesh resolution $\left(-37.33^{\circ}\right)$. An $80 \mathrm{~m}$ mesh does 
not accurately represent elevation and slope, mainly near the extreme elevation values (highs and lows).

The effect of the terrain model on the wind speed, wind direction and turbulent kinetic energy at three locations (SW ridge, valley and NW ridge) and two incoming wind directions (SW and NE) was the following:

1. In the case of SW winds, the mesh resolution effects on the SW ridge were restricted to the first $100 \mathrm{~m}$ a.g.l., where mesh refinement decreased the wind speed and degraded the quantitative agreement with the experimental data, though replicating the profile shape.

2. Separated flow field in the valley is perpendicular to the main flow direction. This region increases in height and length with the mesh refinement.

3. The flow (mainly the wind direction) in the valley was the most affected by terrain resolution; low velocities (about $1 \mathrm{~m} \mathrm{~s}^{-1}$ ) are associated with large variations in wind direction within the first $150 \mathrm{~m}$ a.g.l.

Concerning the digital terrain models and meshes, the conclusions were the following:

1. It was found that 40 and $20 \mathrm{~m}$ meshes are resolutions threshold resolution - beyond which no or insignificant changes occur in terrain attributes, elevation and slope, and in the flow field variables, wind speed, wind direction and turbulent kinetic energy.

2. It is recommended that at least 40 and $20 \mathrm{~m}$ meshes based on military and ALS be used to describe the Perdigão site, with the SRTM restricted to far-away regions.

The conclusions hold under the conditions of the present work, namely terrain data and flow model equations and conditions. Under different conditions, further validation may be required.

Data availability. Three data file types are available. For more information see Palma et al. (2020e).

Aerial survey files (as described in Sect. 2.1):

(1) orthophotos in 5 and $20 \mathrm{~cm}$ resolution (https://doi.org/10.34626/uporto/fvwj-bp86, Palma et al., 2020g),

(2) lidar point cloud data (https://doi.org/10.34626/uporto/fms2rd63, Palma et al., 2020f).

Digital terrain models in local metric datum (as described in Sect. 4):

(1) SRTM raster map of the Perdigão region $(\sim 100 \mathrm{~km}$ square area at resolution of $1 \mathrm{arcsec} ; \approx 24 \mathrm{~m} \times 31 \mathrm{~m}$, easting $\times$ northing; non-uniform; https://doi.org/10.34626/uporto/83wp-kx09, Palma et al., 2020d),

(2) military chart raster map of the Perdigão region $(16 \mathrm{~km} \times 20 \mathrm{~km}$ area at $10 \mathrm{~m}$ resolution; https://doi.org/10.34626/uporto/126h-d173,
Palma et al., 2020c),

(3) ALS-derived raster maps of the Perdigão site ( $\sim 5 \mathrm{~km} \times 6 \mathrm{~km}$ net area at $2 \mathrm{~m}$ resolution, without buildings; https://doi.org/10.34626/uporto/8cj0-dj85, Palma et al., 2020a),

(4) ALS-derived raster maps of Perdigão site ( $5 \mathrm{~km} \times 6 \mathrm{~km}$ net area at $2 \mathrm{~m}$ resolution, with buildings; https://doi.org/10.34626/uporto/88r8-a206, Palma et al., 2020b).

Computational meshes (as described in Sect. 5.2):

(1) NE inflow, $20 \mathrm{~m} \times 20 \mathrm{~m}$ (ALS.NE.20, as in Table 5; https://doi.org/10.34626/uporto/gvtg-0g24, Batista et al., 2020a);

(2) NE inflow, $40 \mathrm{~m} \times 40 \mathrm{~m}$ (ALS.NE.40, as in Table 5; https://doi.org/10.34626/uporto/ybwb-es40, Batista et al., 2020b);

(3) NE inflow, $80 \mathrm{~m} \times 80 \mathrm{~m}$ (ALS.NE.80, as in Table 5; https://doi.org/10.34626/uporto/mwd6-9h81, Batista et al., 2020c);

(4) SW inflow, $20 \mathrm{~m} \times 20 \mathrm{~m}$ (ALS.SW.20, as in Table 5; https://doi.org/10.34626/uporto/4t5v-r909, Batista et al., 2020d);

(5) $\mathrm{SW}$ inflow, $40 \mathrm{~m} \times 40 \mathrm{~m}$ (ALS.SW.40, as in Table 5; https://doi.org/10.34626/uporto/w0jp-jf72, Batista et al., 2020e); (6) SW inflow, $80 \mathrm{~m} \times 80 \mathrm{~m}$ (ALS.SW.80, as in Table 5; https://doi.org/10.34626/uporto/9eaq-4t35, Batista et al., 2020f).

Author contributions. JMLMP conceived, coordinated and was responsible for both the work and the manuscript writing. CAMS carried out the fluid flow calculations under the guidance of VCG and ASL. TS and PC developed the algorithm for building identification. VTPB contributed by processing the terrain data using the LAStools@ software.

Competing interests. The authors declare that they have no conflict of interest.

Special issue statement. This article is part of the special issue "Flow in complex terrain: the Perdigão campaigns (ACP/WES/AMT inter-journal SI)". It is not associated with a conference.

Acknowledgements. The Perdigão-2017 field campaign was primarily funded by the US National Science Foundation, European Commission (ENER/FP7/618122/NEWA), Danish Energy Agency, German Federal Ministry of Economy and Energy, FCT-Portuguese Foundation for Science and Technology (NEWA/1/2014), and US Army Research Laboratory. We are grateful to the municipality of Vila Velha de Ródão; landowners who authorized installation of scientific equipment in their properties, the residents of Vale do Cobrão, Foz do Cobrão, Alvaiade and Chão das Servas; and local businesses who kindly contributed to the success of the campaign. The campaign would not have been possible without the alliance of many persons and entities, too many to be listed here and to whom we are also grateful.

Financial support. This research has been supported by the FCT Fundação para a Ciência e Tecnologia (Portugal; grant no. NEWA/01/2014). 
Review statement. This paper was edited by Jakob Mann and reviewed by Paul van der Laan and one anonymous referee.

\section{References}

Alves, J.: Perdigão Terrestrial Survey (tower 20/tse04), Tech. rep., Low Edge Consult Lda, Portugal, terrestrial survey around tower 20/tse04, by Low Edge Consult Lda, under contract, 2018.

Batista, V., Gomes, V., and Palma, J.: Perdigão: computational mesh (ALS.NE.20), https://doi.org/10.34626/uporto/gvtg-0g24, 2020a.

Batista, V., Gomes, V., and Palma, J.: Perdigão: computational mesh (ALS.NE.40), https://doi.org/10.34626/uporto/ybwb-es40, 2020b.

Batista, V., Gomes, V. and Palma, J.: Perdigão: computational mesh (ALS.NE.80), https://doi.org/10.34626/uporto/mwd6-9h81, 2020c.

Batista, V., Gomes, V., and Palma, J.: Perdigão: computational mesh (ALS.SW.20), https://doi.org/10.34626/uporto/4t5v-r909, 2020d.

Batista, V., Gomes, V., and Palma, J.: Perdigão: computational mesh (ALS.SW.40), https://doi.org/10.34626/uporto/w0jp-jf72, 2020e.

Batista, V., Gomes, V., and Palma, J.: Perdigão: computational mesh (ALS.SW.80), https://doi.org/10.34626/uporto/9eaq-4t35, $2020 \mathrm{f}$.

Carvalho, J.: Stationarity periods during the Perdigão campaign, Master's thesis, Faculty of Engineering of the University of Porto, available at: https://repositorio-aberto.up.pt/bitstream/ 10216/122036/2/348346.pdf (last access: 20 October 2020), 2019.

Castro, F., Palma, J., and Lopes, A. S.: Simulation of the Askervein Flow. Part 1: Reynolds Averaged Navier-Stokes Equations ( $k-$ $\varepsilon$ Turbulence Model), Bound.-Lay. Meteorol., 107, 501-530, https://doi.org/10.1023/A:1022818327584, 2003.

Costa, J., Castro, F., Palma, J., and Stuart, P.: Computer Simulation of Atmospheric Flows over Real Forests for Wind Energy Resource Evaluation, J. Wind Eng. Ind. Aerod., 94, 603-620, https://doi.org/10.1016/j.jweia.2006.02.002, 2006.

Deng, Y., Wilson, J. P., and Bauer, B. O.: DEM resolution dependencies of terrain attributes across a landscape, International Journal of Geographical Information Science, 21, 187213, https://doi.org/10.1080/13658810600894364, 2007.

DeWitt, J. D., Warner, T. A., and Conley, J. F.: Comparison of DEMS derived from USGS DLG, SRTM, a statewide photogrammetry program, ASTER GDEM and LiDAR: implications for change detection, GIScience Remote Sensing, Taylor \& Francis _eprint, 52, 179-197, https://doi.org/10.1080/15481603.2015.1019708, 2015.

DGT: ReNEP: The Portuguese Network of Continuously Operating Reference Stations Status, Products and Services, available at: http://renep.dgterritorio.gov.pt (last access: 20 October 2020), 2017 (in Portuguese).

Diebold, M., Higgins, C., Fang, J., Bechmann, A., and Parlange, M. B.: Flow over Hills: A Large-Eddy Simulation of the Bolund Case, Bound.-Lay. Meteorol., 148, 177-194, https://doi.org/10.1007/s10546-013-9807-0, 2013.

Farr, T., Rosen, P., Caro, E., Crippen, R., Duren, R., Hensley, S., Kobrick, M., Paller, M., Rodriguez, E., Roth, L., Seal, D., Shaffer,
S., Shimada, J., Umland, J., Werner, M., Oskin, M., Burbank, D., and Alsdorf, D.: The Shuttle Radar Topography Mission, Rev. Geophys., 45, RG2004, https://doi.org/10.1029/2005RG000183, 2007.

Fernando, H., Mann, J., Palma, J., Lundquist, J., Barthelmie, R., Belo-Pereira, M., Brown, W., Chow, F. K., Gerz, T., Hocut, C., Klein, P., Leo, L., Matos, J., Oncley, S., Pryor, S., Bariteau, L., Bell, T., Bodini, N., Carney, M., Courtney, M., Creegan, E., Dimitrova, R., Gomes, S., Hagen, M., Hyde, J., Kigle, S., Krishnamurthy, R., Lopes, J., Mazzaro, L., Neher, J., Menke, R., Murphy, P., Oswald, L., Otarola-Bustos, S., Pattantyus, A., Rodrigues, C. V., Schady, A., Sirin, N., Spuler, S., Svensson, E., Tomaszewski, J., Turner, D., van Veen, L., Vasiljević, N., Vassallo, D., Voss, S., Wildmann, N., and Wang, Y.: The Perdigão: Peering into Microscale Details of Mountain Winds, B. Am. Meteorol. Soc., 100, 799-819, https://doi.org/10.1175/BAMSD-17-0227.1, 2019.

Florinsky, I. and Kuryakova, G.: Determination of grid size for digital terrain modelling in landscape investigations-exemplified by soil moisture distribution at a micro-scale, Int. J. Geogr. Inf. Sci., 14, 815-832, https://doi.org/10.1080/136588100750022804, 2000.

Gomes, V. and Palma, J.: Computational modelling of a large dimension wind farm cluster using domain coupling, Journal of Physics: Conference Series, 753, 082032, http://stacks.iop.org/ 1742-6596/753/i=8/a=082032 (last access: 20 October 2020), 2016.

Gomes, V. C., Palma, J., and Silva Lopes, A.: Improving actuator disk wake model, Journal of Physics: Conference Series, 524, 012170, https://doi.org/10.1088/1742-6596/524/1/012170, 2014.

Hawker, L., Bates, P., Neal, J., and Rougier, J.: Perspectives on Digital Elevation Model (DEM) Simulation for Flood Modeling in the Absence of a High-Accuracy Open Access Global DEM, Front. Earth Sci., 6, https://doi.org/10.3389/feart.2018.00233, 2018.

Lange, J., Mann, J., Berg, J., Parvu, D., Kilpatrick, R., Costache, A., Chowdhury, J., Siddiqui, K., and Hangan, H.: For wind turbines in complex terrain, the devil is in the detail, Environ. Res. Lett. 12, 094020, https://doi.org/10.1088/1748-9326/aa81db, 2017.

LAStools: Efficient LiDAR Processing Software (version 190927, academic), available at: http://rapidlasso.com (last access: 20 October 2020), 2019.

Mahalingam, R. and Olsen, M. J.: Evaluation of the influence of source and spatial resolution of DEMs on derivative products used in landslide mapping, Geomatics, Natural Hazards and Risk, 7, 1835-1855, https://doi.org/10.1080/19475705.2015.1115431, 2016.

Mallet, C. and Bretar, F.: Full-waveform topographic lidar: State-ofthe-art, ISPRS Journal of Photogrammetry and Remote Sensing, 64, 1-16, https://doi.org/10.1016/j.isprsjprs.2008.09.007, 2009.

Mandelbrot, B.: How long is the coast of Britain? Statistical selfsimilariry and fractional dimension, Science, 156, 636-638, https://doi.org/10.1126/science.156.3775.636, 1967.

Mandelbrot, B.: The Fractal Geometry of Nature, W.H. Freeman and Company, New York, updated edn., 1982.

Mann, J., Angelou, N., Arnqvist, J., Callies, D., Cantero, E., Arroyo, R. C., Courtney, M., Cuxart, J., Dellwik, E., Gottschall, J., Ivanell, S., Kuhn, P., Lea, G., Matos, J., Rodrigues, C., Palma, J., Pauscher, L., Peña, A., Rodrigo, J., Söderberg, S., 
and Vasiljević, N.: Complex terrain experiments in the New European Wind Atlas, Philos. T. R. Soc. A, 375, 20160101, https://doi.org/10.1098/rsta.2016.0101, 2017.

Menke, R., Vasiljević, N., Mann, J., and Lundquist, J. K.: Characterization of flow recirculation zones at the Perdigão site using multi-lidar measurements, Atmos. Chem. Phys., 19, 2713-2723, https://doi.org/10.5194/acp-19-2713-2019, 2019.

Mortensen, N., Landberg, L., Troen, I., Petersen, E., Rathmann, O., and Nielsen, M.: WAsP Utility Programs, Tech. Rep. Risø-R995(EN), Risø National Laboratory, Roskilde, Denmark, available at: http://orbit.dtu.dk/files/106312446/ris_i_2261.pdf (last access: 20 October 2020), 2004.

Mukherjee, S., Joshi, P. K., Mukherjee, S., Ghosh, A., Garg, R. D., and Mukhopadhyay, A.: Evaluation of vertical accuracy of open source Digital Elevation Model (DEM), Int. J. Appl. Earth Obs., 21, 205-217, https://doi.org/10.1016/j.jag.2012.09.004, 2013.

Nikora, V. and Goring, D.: Mars topography: bulk statistics and spectral scaling, Chaos, Solitons \& Fractals, 19, 427-439, https://doi.org/10.1016/S0960-0779(03)00054-7, 2004.

NIRAS: Perdigão Aerial Survey, Tech. rep., NIRAS, available at: https://windsptds.fe.up.pt//thredds/fileServer/ landCharacterization/AerialSurveyLidarandPhotographyData/ PortugalLaserscanningReport.pdf (last access: 20 October 2020), 2015.

Palma, J., Castro, F., Ribeiro, L., Rodrigues, A., and Pinto, A.: Linear and nonlinear models in wind resource assessment and wind turbine micro-siting in complex terrain, J. Wind Eng. Ind. Aerod., 96, 2308-2326, https://doi.org/10.1016/j.jweia.2008.03.012, 2008.

Palma, J., Menke, R., Mann, J., Oncley, S., Matos, J., and Silva Lopes, A.: Perdigão-2017: experiment layout (Version 1), Tech. rep., NEWA: New European Wind Atlas (FCT Project number NEWA/0001/2014), available at: https://perdigao.fe.up.pt/ api/documents/versions/307?download (last access: 20 October 2020), 2018.

Palma, J., Batista, V., and Gomes, V.: Perdigão: aerial lidar survey raster map, https://doi.org/10.34626/uporto/8cj0-dj85, 2020a.

Palma, J., Batista, V. and Gomes, V.: Perdigão: aerial lidar survey raster map (with buildings), https://doi.org/10.34626/uporto/88r8-a206, 2020b.

Palma, J., Batista, V., and Gomes, V.: Perdigão: Military charts raster map of perdigão region, https://doi.org/10.34626/uporto/126h-d173, 2020c.

Palma, J., Batista, V., and Gomes, V. Perdigão: SRTM raster map, https://doi.org/10.34626/uporto/83wp-kx09, 2020d.

Palma, J., Batista, V., Gomes, V., Lopes, J., Mann, and Dellwik, E.: Land characterisation of the Perdigão site: data guide. Technical report, University of Porto and Technical University of Denmark, 6, available at: https://perdigao.fe.up.pt/api/documents/versions/ 353?download, last access: 21 October 2020e.

Palma, J., Batista, V., Gomes, V., Lopes, J., Mann, J., and Dellwik, E.: Perdigão: Lidar point cloud, https://doi.org/10.34626/uporto/fms2-rd63, 2020f.

Palma, J., Batista, V., Gomes, V., Lopes, J., Mann, J., and Dellwik, E.: Perdigão: Ortophotos in $5 \mathrm{~cm}$ and $20 \mathrm{~cm}$ resolution, https://doi.org/10.34626/uporto/fvwj-bp86, 2020g.

Roache, P. J.: Verification and Validation in Computational Science and Engineering, Hermosa Publishers, Albuquerque, USA, 1998.
Savage, J., Bates, P., Freer, J., Neal, J., and Aronica, G.: When does spatial resolution become spurious in probabilistic flood inundation predictions?, Hydrological Processes, John Wiley \& Sons, Ltd, 30, 2014-2032, https://doi.org/10.1002/hyp.10749, 2016.

Silva, C.: Computational study of atmospheric flows over Perdigão: terrain resolution and domain size, Master's thesis, Faculty of Engineering of the University of Porto, available at: https://hdl. handle.net/10216/113854 (last access: 20 October 2020), 2018.

Simpson, A., Balog, S., Moller, D. K., Strauss, B., and Saito, K.: An urgent case for higher resolution digital elevation models in the world's poorest and most vulnerable countries, Front. Earth Sci., 3, https://doi.org/10.3389/feart.2015.00050, 2015.

Stull, R.: An Introduction to Boundary Layer Meteorology, Atmospheric and Oceanographic Sciences Library, Springer Netherlands, https://doi.org/10.1007/978-94-009-3027-8, 1988.

UCAR/NCAR-EOL: NCAR/EOL Quality Controlled 5-minute ISFS surface flux data, geographic coordinate, tilt corrected, https://doi.org/10.26023/ZDMJ-D1TY-FG14, 2019.

Vasiljević, N., L. M. Palma, J. M., Angelou, N., Carlos Matos, J., Menke, R., Lea, G., Mann, J., Courtney, M., Frölen Ribeiro, L., and M. G. C. Gomes, V. M.: Perdigão 2015: methodology for atmospheric multi-Doppler lidar experiments, Atmos. Meas. Tech., 10, 3463-3483, https://doi.org/10.5194/amt-103463-2017, 2017.

Wagner, J., Gerz, T., Wildmann, N., and Gramitzky, K.: Longterm simulation of the boundary layer flow over the doubleridge site during the Perdigão 2017 field campaign, Atmos. Chem. Phys., 19, 1129-1146, https://doi.org/10.5194/acp-191129-2019, 2019.

Wise, S.: Assessing the quality for hydrological applications of digital elevation models derived from contours, Hydrol. Process., 14, 1909-1929, https://doi.org/10.1002/10991085(20000815/30)14:11/12<1909::AID-HYP45>3.0.CO;2-6, 2000.

Wood, N.: The onset of separation in neutral, turbulent flow over hills, Bound.-Lay. Meteorol., 76, 137-164, https://doi.org/10.1007/BF00710894, 1995.

Yamaguchi, Y., Kahle, A., Tsu, H., Kawakami, T., and Pniel, M.: Overview of Advanced Spaceborne Thermal Emission and Reflection Radiometer (ASTER), IEEE T. Geosci. Remote, 36, 1062-1071, https://doi.org/10.1109/36.700991, 1998.

Zhang, W. and Montgomery, D. R.: Digital elevation model grid size, landscape representation, and hydrologic simulations, Water Resour. Res., 30, 1019-1028, https://doi.org/10.1029/93WR03553, 1994. 